\title{
A Numerical Investigation of the Gulf Stream and Its Meanders in Response to Cold Air Outbreaks
}

\author{
HuiJIE XUE \\ School of Marine Sciences, University of Maine, Orono, Maine \\ JOHN M. BANE JR. \\ Marine Sciences Program, University of North Carolina, Chapel Hill, North Carolina
}

(Manuscript received 11 October 1996, in final form 5 May 1997)

\begin{abstract}
The three-dimensional Princeton Ocean Model is used to examine the modification of the Gulf Stream and its meanders by cold air outbreaks. Two types of Gulf Stream meanders are found in the model. Meanders on the shoreward side of the Gulf Stream are baroclinically unstable. They are affected little by the atmospheric forcing because their energy source is stored at the permanent thermocline, well below the influence of the surface forcing. Meanders on the seaward side of the stream are both barotropically and baroclinically unstable. The energy feeding these meanders is stored at the surface front separating the Gulf Stream and the Sargasso Sea, which is greatly reduced in case of cold air outbreaks. Thus, meanders there reduce strength and also seem to slow their downstream propagation due to the southward Ekman flow. Heat budget calculations suggest two almost separable processes. The oceanic heat released to the atmosphere during these severe cooling episodes comes almost exclusively from the upper water column. Transport of heat by meanders from the Gulf Stream to the shelf, though it is large, does not disrupt the principal balance. It is balanced nicely with the net heat transport in the downstream direction.
\end{abstract}

\section{Introduction}

Climatologically, the largest transfers of sensible and latent heat from the ocean to the atmosphere occur off the east coast of the United States along the Gulf Stream sea surface temperature front during winter (Budyko 1974; Isemer and Hasse 1987; Schmitt et al. 1989). A substantial part of these transfers takes place during the cold-air outbreak phase of passing atmospheric cyclones. As cold, dry, Arctic air flows off of the continent and over the warm Gulf Stream, instantaneous transfer rates can exceed climatological values by several times (Xue et al. 1995).

These excessive, ocean-to-atmosphere heat and moisture fluxes play an important role in coastal frontogenesis and cyclogenesis in the atmosphere. The near-surface momentum and heat fluxes are relatively low over the cool continental shelf water but higher over the Gulf Stream and Sargasso Sea (Bane and Osgood 1989; Grossman and Betts 1990). Such a differential heating destabilizes the atmospheric thermal field over the warm water, and a low-level baroclinic zone develops at the

Corresponding author address: Dr. Huijie Xue, School of Marine Sciences, University of Maine, Room 218, 5741 Libby Hall, Orono, ME 04469-5741. boundary between the Gulf Stream water and the cooler shelf water (Doyle and Warner 1990, 1993; Hobbs 1987; Huang and Raman 1992). The coupling of the lower and upper troposphere is enhanced by weak vertical and slantwise stability. When a weak midtroposphere wave superimposes on the low-level baroclinic zone, a cyclone can develop rapidly (Holt and Raman 1990; Newton and Holopainen 1990; Wash et al. 1990).

These heat and moisture fluxes also significantly modify underlying oceanic conditions. Atkinson et al. (1989) and Lee et al. (1989) found that during the Genesis of Atlantic Lows Experiment (GALE), the shelf within the South Atlantic Bight (SAB) was well mixed much of the time, indicating the effectiveness of wind mixing and heat loss. The position of the midshelf front was significantly affected by the advection of coastal waters offshore or Gulf Stream waters onshore. A heat budget calculation on the shelf showed that the observed heat content variability was caused by intrusion of Gulf Stream water, and the intrusion may be induced either by onshore Ekman flow during southward winds or by Gulf Stream meandering events. In contrast, the heat budget in the Gulf Stream just off the shelf in the SAB demonstrated a different balance during cold air outbreaks. The results of outbreaks (Goodman 1990) clearly showed that the latent plus sensible heat transfer to the atmosphere from the Gulf Stream during a severe 
cold-air outbreak was balanced by the cooling within the Gulf Stream's mixed layer. Even in the swift Gulf Stream, the warm water flowing from the south does not significantly affect this essentially one-dimensional heat balance during strong thermal forcing, in part because of the large alongstream scale of the atmospheric cooling.

Consistent with the observed heat budget analysis of Goodman (1990), the modeled heat budget analysis of Xue et al. (1995) showed that the cooling is so strong and rapid that loss of oceanic heat cannot be offset by any other process present in the heat budget. Similarly, Kelly and Qiu (1995) found that in the western North Atlantic the temperature tendency and the surface heating term were the dominant terms in the upper-ocean temperature equation. However, they also pointed out that advection could become important in and north of the Gulf Stream. That the advection becomes important is likely due to the predominantly alongstream westerly winds in the region downstream of Cape Hatteras, which cause the jet to be displaced southward (Adamec and Elsberry 1985). In the SAB, however, westerly winds are primarily perpendicular to the flow of the Gulf Stream. These winds could decelerate the stream, but their effect on the heat budget cannot be determined from the two-dimensional studies of Xue et al. (1995).

It was observed in the Gulf Stream during GALE that the most noticeable responses to surface heat fluxes were a deepening of the mixed layer and a decrease in mixed layer temperature (Bane and Osgood 1989). Xue et al. (1995) suggested that such responses result from the excessive cooling rate associated with cold air outbreaks and the long stretch of the cold air mass in the alongstream direction. No direct current measurements were made in the stream during GALE. The study by Worthington $(1976,1977)$ attributed an increase in volume transport in the Gulf Stream to oceanic heat loss to the cold continental air moving offshore in winter. Huang (1990) suggested that the vertical mixing of momentum after a cooling event would reduce surface currents yet increase the volume transport, which suggests that the response below the mixed layer might be quite different from the surface response.

Adamec and Elsberry (1985) and Xue et al. (1995) both showed that the downstream momentum tends to mix within the oceanic boundary layer in response to intensive cooling, thereby causing the surface currents to decelerate and the currents immediately below the surface to accelerate. A thermally direct vertical circulation appears and tends to weaken the horizontal temperature gradient at the front, in contrast to the reinforcement of the temperature gradient at the front found by Nof (1983) using a steady current. The cross-stream circulation is dominated by Ekman-like motion driven by downstream winds with horizontal velocities on the order of $10 \mathrm{~cm} \mathrm{~s}^{-1}$ and vertical velocities on the order of $0.1 \mathrm{~cm} \mathrm{~s}^{-1}$. However, the net displacement of the stream was smaller in Xue et al. (1995) because they considered a continuously rotating wind direction as the storm moved away. In addition, Xue et al. (1995) found a vertical circulation cell within the Gulf Stream resulting from the convergence/divergence pattern of the Ekman transport due to the altered inertial frequency, which is caused by the horizontal velocity shear of the Gulf Stream.

Differences in the prestorm oceanic setting can also affect the oceanic modifications due to atmospheric storms. For example, in the northeast Pacific during the Ocean Storms Experiment, Large and Crawford (1995) found that for a rather shallow thermocline, wind mixing eroded the thermocline and generated a downward heat flux that cooled the mixed layer. In contrast, in the SAB during GALE, except on the shelf, vertical mixing did not reach the thermocline and thus the downward heat flux was small. It was the heat loss to the atmosphere that cooled the mixed layer.

A dynamically interesting characteristic of the Gulf Stream in the SAB is its meanders (Webster 1961; Bane et al. 1981; Lee et al. 1981). It is of interest to understand the roles that meanders play in determining the Gulf Stream heat budget. Additionally, the adjustment in upper-ocean thermal structure caused by the surface heat flux may alter the stability of the Gulf Stream front and thereby affect the growth of meanders along the front. In this paper a three-dimensional model is used to simulate the modifications of the Gulf Stream and adjacent shelf waters caused by winter storms moving out to sea. It naturally extends the two-dimensional work of Xue et al. (1995), yet differs in a very important way. The three-dimensional model allows for frontal instability, and thus interactions can occur between meanders and the atmospherically driven motions. Furthermore, the addition of the third dimension in the downstream direction allows the importance of the downstream heat transport in the heat budget to be assessed.

Descriptions of the model and boundary conditions are given in section 2. Results of four numerical experiments are presented in section 3; these address the response of the meandering stream to wind and heat flux forcing during a model winter storm. Section 4 discusses the momentum, energy, and heat budgets calculated from the model results.

\section{The model}

The three-dimensional Princeton Ocean Model (POM) is used to investigate the evolution of the oceanic mixed layer and the upper ocean in response to intensive cooling and wind forcing, typical of a wintertime cold air outbreak. The embedded, second-order turbulence closure scheme in the POM is effective in describing the transformation of the oceanic mixed layer due to either convective mixing or wind mixing (Large and Crawford 1995; Martin 1985; Xue et al. 1995). The model has also been successfully used to simulate Gulf Stream meanders in the SAB (Xue 1991). Details on 
the model algorithm can be found in Blumberg and Mellor (1987).

The model, in a topography-following $\sigma$ coordinate that also accommodates the time-dependent surface elevation, numerically solves the momentum equations

$$
\begin{aligned}
\frac{\partial u}{\partial t}+\mathbf{v} \cdot \nabla u+w \frac{\partial u}{\partial z}-f v= & -\frac{1}{\rho_{0}} \frac{\partial p}{\partial x} \\
& +\frac{\partial}{\partial z}\left(K_{M} \frac{\partial u}{\partial z}\right)+F_{x} \\
\frac{\partial v}{\partial t}+\mathbf{v} \cdot \nabla v+w \frac{\partial v}{\partial z}+f u= & -\frac{1}{\rho_{0}} \frac{\partial p}{\partial y} \\
& +\frac{\partial}{\partial z}\left(K_{M} \frac{\partial v}{\partial z}\right)+F_{y} \\
\rho g= & -\frac{\partial p}{\partial z}
\end{aligned}
$$

along with the continuity equation

$$
\frac{\partial u}{\partial x}+\frac{\partial v}{\partial y}+\frac{\partial w}{\partial z}=0
$$

and the potential temperature equation

$$
\frac{\partial \theta}{\partial t}+\mathbf{v} \cdot \boldsymbol{\nabla} \theta+w \frac{\partial \theta}{\partial z}=\frac{\partial}{\partial z}\left(K_{H} \frac{\partial \theta}{\partial z}\right)+F_{\theta}
$$

coupled with an equation of state $\rho=\rho(\theta, S, p)$ (Mellor 1991). A constant salinity $(S)$ of 35 psu is used in the present study. Here $\mathbf{v}=u \mathbf{i}+v \mathbf{j} ; F_{x}, F_{y}$, and $F_{\theta}$ are related to the small-scale mixing processes not directly resolved by the model and are parameterized as horizontal diffusion (Smagorinsky 1963); other notations are conventional. The governing equations also contain parameterized Reynolds stresses and heat fluxes, based on the work of Mellor and Yamada (1982). These account for the turbulent diffusion of momentum and heat in the vertical. The vertical mixing coefficients, $K_{M}$ and $K_{H}$, are obtained by appealing to a second-order turbulence closure, which characterizes the turbulence through equations for the turbulence kinetic energy, $q^{2} / 2$, and a turbulence macroscale, $L$.

Boundary conditions at the free surface are

$$
\begin{aligned}
\rho_{o} K_{M} \frac{\partial}{\partial z}(u, v) & =\left(\tau_{x}, \tau_{y}\right) ; & & \mathrm{c} \rho_{o} K_{H} \frac{\partial \theta}{\partial z}=Q ; \\
q^{2} & =\frac{1}{\rho_{o}}|\tau| B_{1}^{-2 / 3} ; & q^{2} L=0 ; & \text { and } \omega=0,
\end{aligned}
$$

where $\omega$ is the vertical velocity in the $\sigma$-coordinate system and $B_{1}=16.6$, a basic constant of the turbulence closure model; $\boldsymbol{\tau}=\left(\tau_{x}, \tau_{v}\right)$ is the wind stress vector, $c$ is the specific heat of seawater, and $\mathrm{Q}$ is the surface heat flux. Zero mass and zero heat flux are prescribed at the bottom and at the coast. Approximations at open boundaries are critical to the simulation. Mellor (1996)

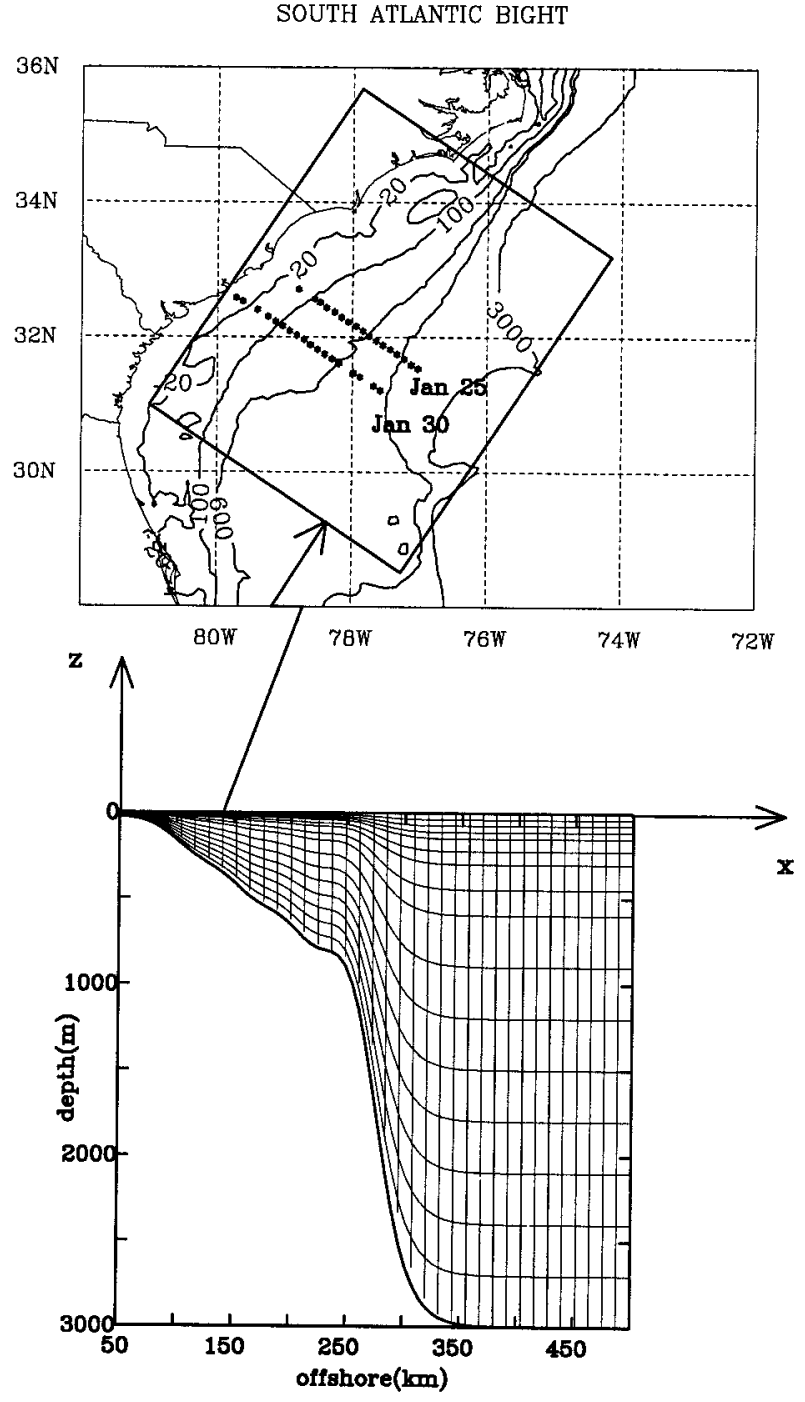

FIG. 1. Map of the study area showing the AXBT deployments during GALE IOP2. A total of 36 AXBTs were deployed along two flight tracks made on 25 and 30 January 1986. A rectangular model domain has been placed on the map. It has a uniform cross section in the alongshore direction. The lower panel shows the cross section and model grids at half of the resolution both in the offshore direction and in the vertical.

lists various options. Appendix A describes the set of open boundary conditions used in this study.

An idealized rectangular domain is used (Fig. 1). The offshore scale of the domain is $450 \mathrm{~km}$, and like in Xue et al. (1995), the coast is placed at $x=50 \mathrm{~km}$. The alongshore scale is $1200 \mathrm{~km}$, a scale chosen to minimize the cutoff of cooling at the southern boundary since the inflow always carries water with the same temperature as the initial condition. The topography is a smoothed version of that taken at the GALE aircraft track of 25 January. Horizontal resolution used in this study is 6 $\mathrm{km}$ in the cross-shore direction by $12 \mathrm{~km}$ in the alongshore direction. There are 33 levels in the vertical, pro- 


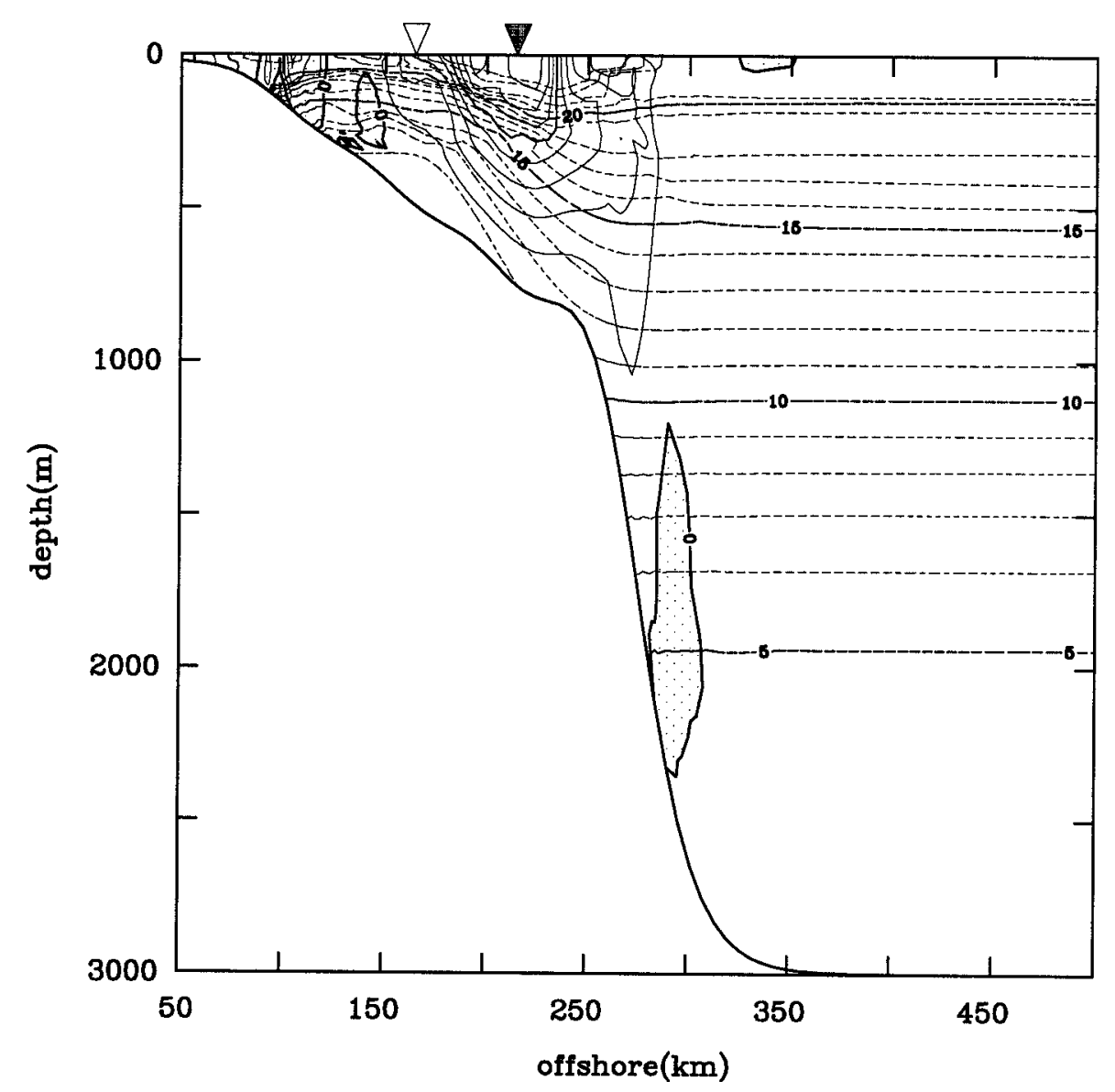

FIG. 2. Temperature and the thermal-wind-balanced downstream velocity used to initialize the Gulf Stream in the model. The observed temperature on 25 January 1986, which is available in the region from $50 \mathrm{~km}$ to $350 \mathrm{~km}$ offshore and from the surface to $300-\mathrm{m}$ depth, is patched to an analytical function that determines the temperature distribution for the rest of the domain. Contour intervals are $1{ }^{\circ} \mathrm{C}$ and $0.2 \mathrm{~m} \mathrm{~s}^{-1}$. The open and solid triangles indicate locations of the shoreward side surface front and the core of the initial Gulf Stream, respectively (adapted from Xue et al. 1995).

viding a resolution of about $10 \mathrm{~m}$ within the upper 100 $\mathrm{m}$ of the Gulf Stream.

The model is initialized using the Gulf Stream cross section of Xue et al. (1995) (Fig. 2), in which the observed temperature of 25 January 1986 is used in the upper $350 \mathrm{~m}$, and that is patched onto a prescribed temperature field at deeper levels. The downstream velocity is in thermal-wind balance with the cross-shore temperature distribution. Zero velocity has been assumed at the bottom to allow the thermal wind relation to be integrated in the vertical; $u$ and $w$ are set to zero. The initial Gulf Stream is uniform in the alongshore direction. The vertical average of these velocity components is used to initialize their barotropic counterparts. The initial surface elevation is obtained from the vertically integrated geostrophic relationship.

The model is first integrated without imposing any external forcing-that is, $\boldsymbol{\tau}=0$ and $Q=0$. A time sequence of the surface temperature (Fig. 3) shows that meanders develop fully along the Gulf Stream front in about ten days. While meandering, the Gulf Stream flows downstream in alternating patterns of an intense offshore current followed by a broader flow onshore. A typical meander pattern is depicted in Fig. 4. Along its shoreward edge, a southwestward excursion of warm Gulf Stream water flows onto the shelf (the warm filament). This is accompanied by an entrainment of cooler water (the cold dome) between the warm filament and the stream. A warm filament reaches only a few tens of meters deep, whereas a cold water dome usually extends to a depth more than $200 \mathrm{~m}$ and spreads shoreward beneath the warm filament. Flows within the warm filament are primarily southward, whereas flows within the cold dome form a cyclonic circulation. Intense upwelling leads the cold dome in the meander propagation direction, which favors the baroclinic instability. Satellite images of 22 and 31 January 1986 suggest the presence of meanders in the GALE study region. However, observations during that particular period are limited and not adequate to map these meanders to be com- 

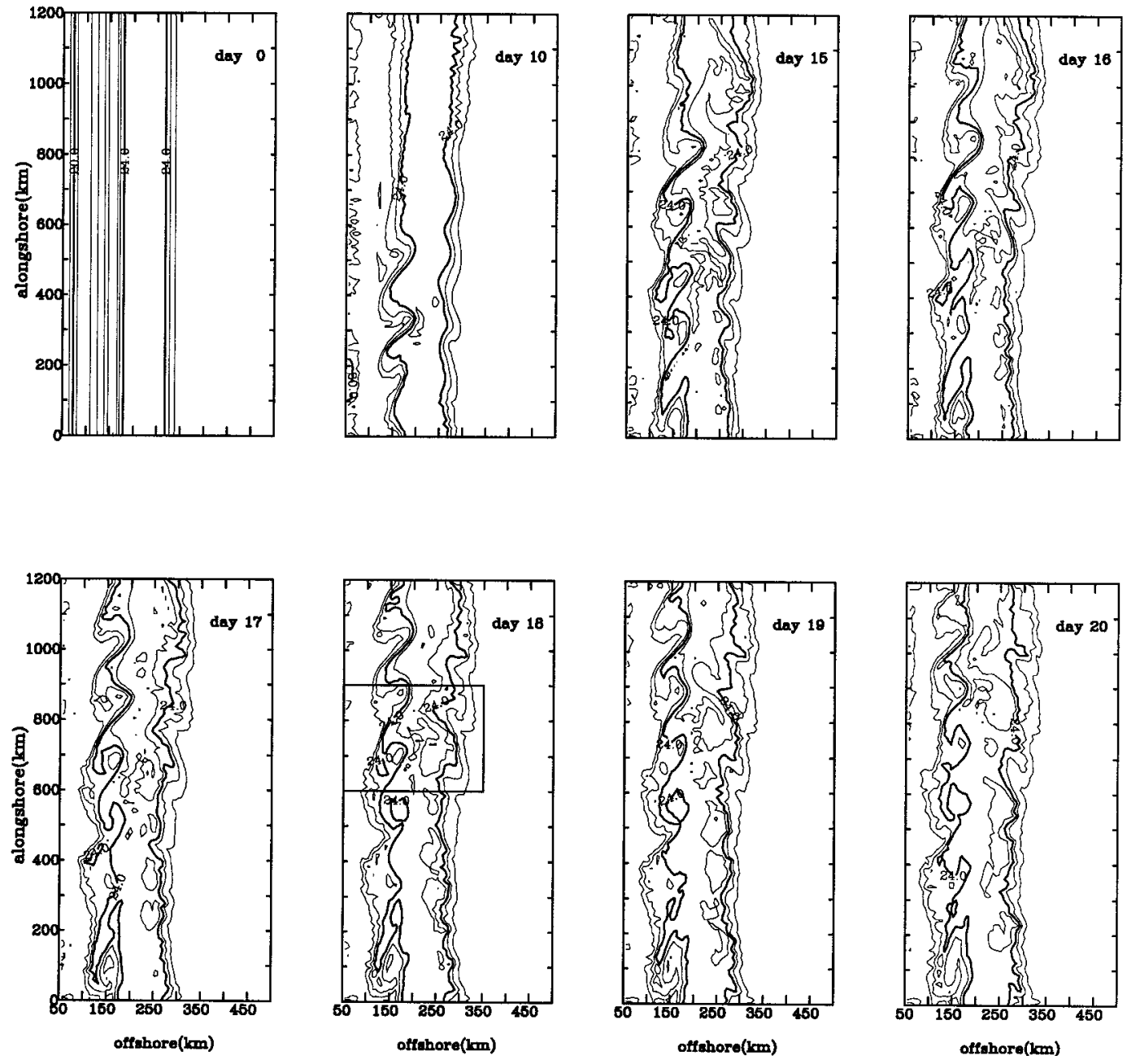

FIG. 3. Time sequence of the temperature at the first $\sigma$ level in the unforced experiment. The depth of the first $\sigma$ level changes from a few centimeters depth at the coast to about $9 \mathrm{~m}$ offshore. Temperature at the this level is hence termed the surface temperature. A subdomain of interest that contains well-developed meanders is highlighted by a $300 \mathrm{~km} \times 300 \mathrm{~km}$ square. Many figures hereafter show distributions in this subdomain only.

pared with model simulated meanders. Nevertheless, the synoptic structure of the modeled meanders seen in Fig. 4 and an averaged wavelength of $200 \mathrm{~km}$ correspond well with meanders observed by Bane et al. (1981) and Lee et al. (1981).

\section{Atmospherically forced responses}

As an atmospheric cold front sweeps offshore, coherent heat and momentum flux patterns result in the alongshore direction (Blanton et al. 1989). These fluxes vary greatly with time and in the offshore direction, however, as seen in Fig. 5. Xue et al. (1995) discussed the variations in heat fluxes in detail and proposed two analytical functions to simulate the spatiotemporal patterns of the heat flux and the surface wind fields. These are adopted in the present study (Fig. 6). It is obvious that these features account for the first-order characteristics of the surface forcing fields induced by intense atmospheric winter storms in this area. Three forced

FIG. 4. A typical meander moving downstream along the shoreward side Gulf Stream front. (a) Surface temperature and velocity, and the vertical velocity at $200 \mathrm{~m}$. The three horizontal lines indicate the leading portion of the meander trough $(y=756 \mathrm{~km})$, the trough $(y=720$ $\mathrm{km})$, and the leading portion of the crest $(y=684 \mathrm{~km})$. Cross-sectional distributions of temperature, $u, w$, and downstream velocity $v$ at these three locations are shown in (b), in which vertical velocity has been multiplied by a factor of 1000 . Contour intervals are $1{ }^{\circ} \mathrm{C}$ for temperature, $0.25 \mathrm{~mm} \mathrm{~s}^{-1}$ for vertical velocity, and $0.1 \mathrm{~m} \mathrm{~s}^{-1}$ for downstream velocity. Stippled areas indicate downwelling in (a) and southward flows in (b). 

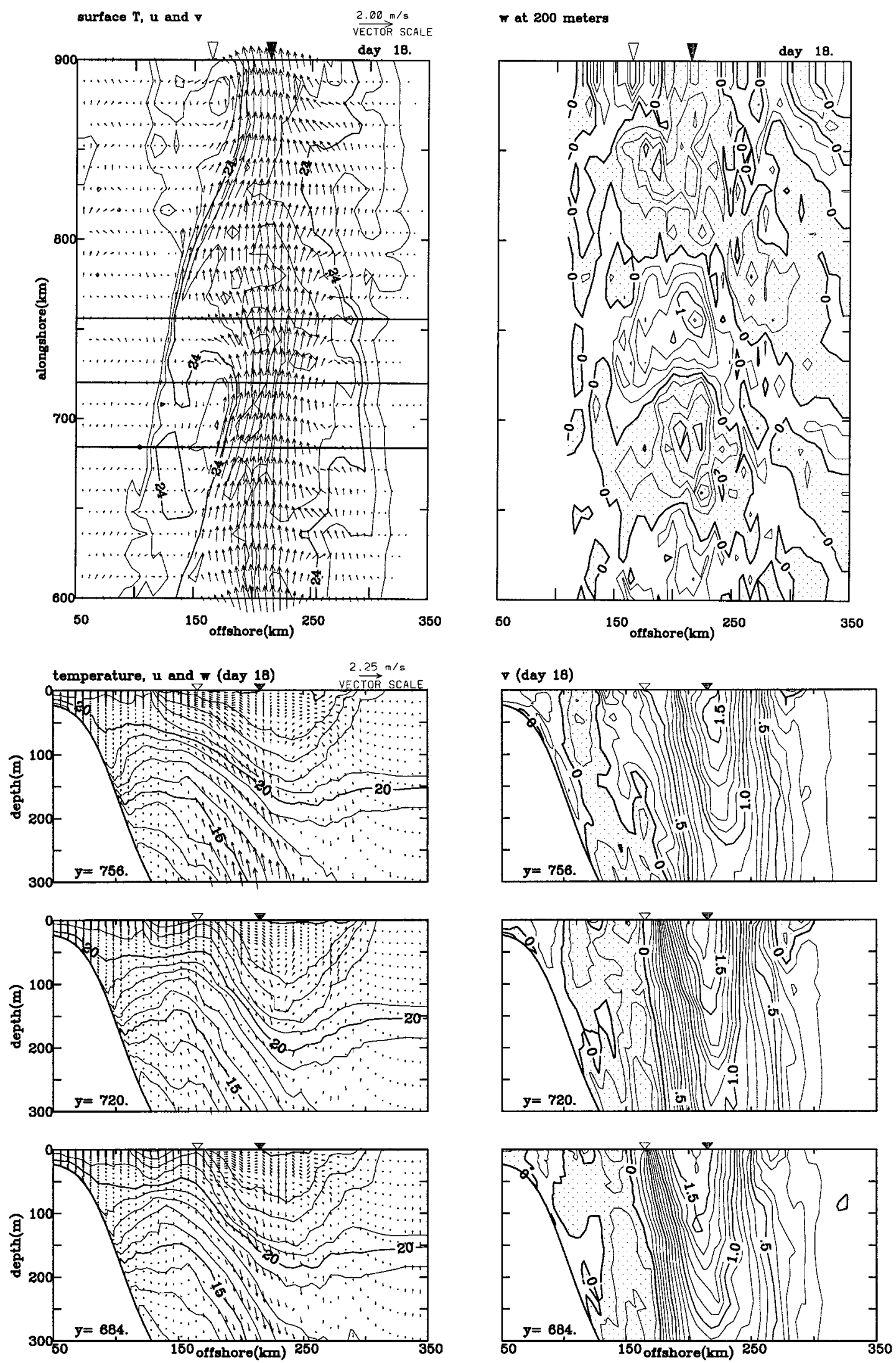


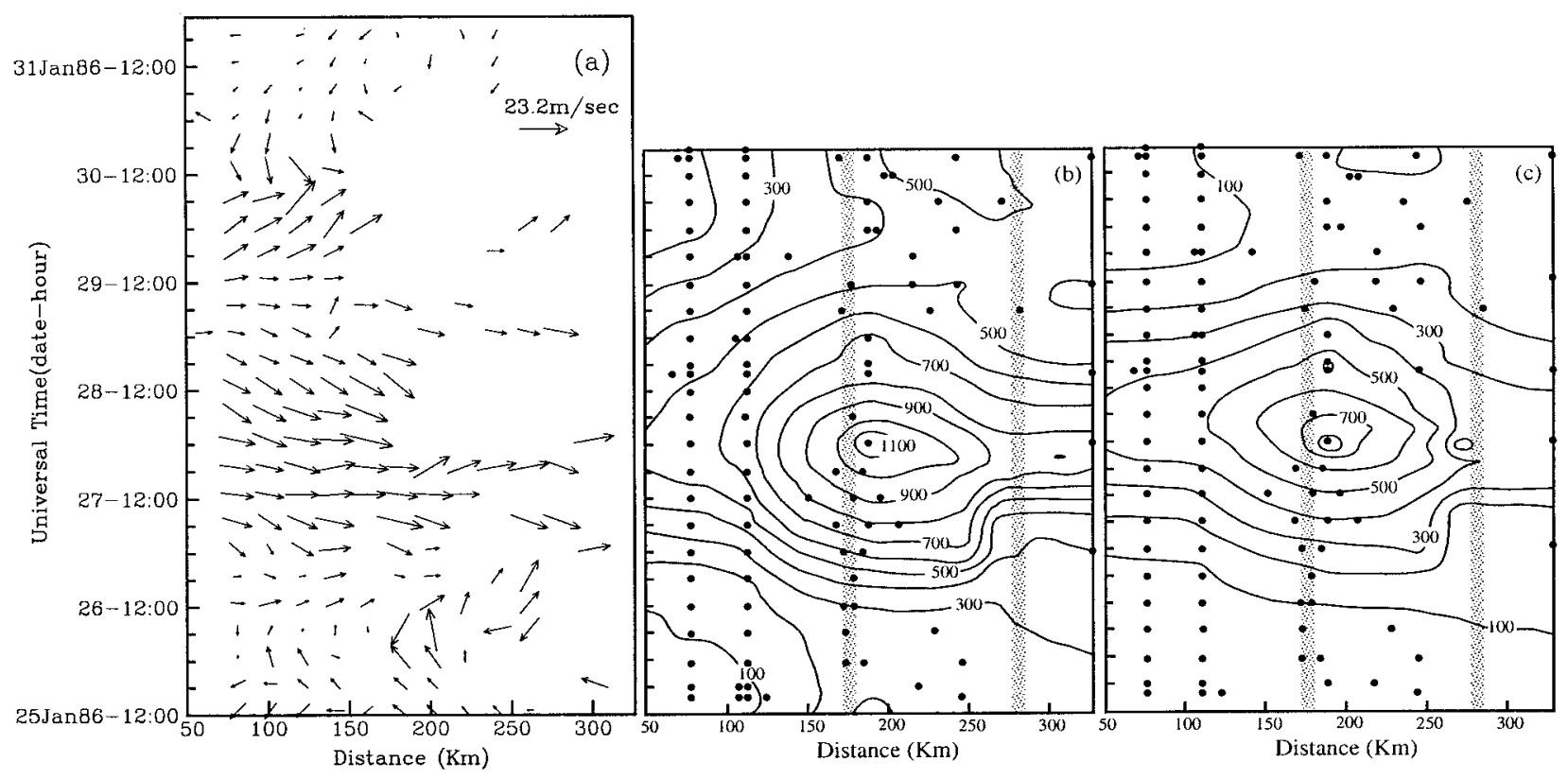

FIG. 5. Spatiotemporal variations of the winds (a), latent heat (b), and sensible heat (c) along a line situated midway between the two flight lines shown in Fig. 1. Sources of data include meteorological buoys, the research aircraft flights, and ships. Winds have been adjusted to the 10-m height above the sea surface using the technique given in Blanton et al. (1989). (b) and (c) Adapted from Xue et al. (1995). Contour interval is $100 \mathrm{~W} \mathrm{~m}^{-2}$.

experiments, the "cooling" experiment with the heat flux only, the "wind" experiment with the wind stress only, and the "combined" experiment with both heat flux and wind stress, have been performed. In all three forced experiments the forcing is initiated at day 15 . Below we first describe the evolution of the Gulf Stream front and the transformations of the oceanic mixed layer. We then examine the heat-flux-induced and the winddriven circulation and their interactions with the meander-induced circulation seen in Fig. 4.

A time sequence of the sea surface temperature (SST) field during a single storm cycle (day 15 to day 20 in the model) for the combined experiment is shown in Fig. 7. The most obvious response is the decrease of SST, which is largely due to oceanic heat loss. More importantly, meanders seem to maintain their wavelengths and propagation speeds despite the vigorous atmospheric forcing. Locations of meander troughs and crests, as seen in the SST patterns, appear to be not affected by the atmospheric event. Further evidence of little change in meander characteristics can be seen in Fig. 8, which shows temperature and the three velocity components for the combined experiment. When compared with the unforced experiment shown in Fig. 4, neither the location nor the magnitude of upwelling and downwelling associated with the passing meanders change. More details about the effects of the atmospheric event on meanders can be seen in Fig. 10 shown later.

The deepening of the mixed layer and the decrease in mixed layer temperature are clearly shown in the forced experiment (Fig. 8b) when compared with Fig. 4b. They are largely due to the enhanced convective mixing associated with surface cooling. Winds can also result in temperature changes in the mixed layer by moving the stream laterally (to be discussed later). Effects of enhanced vertical mixing can also be seen in the downstream velocity in that velocity isopleths are nearly vertical within the mixed layer. This results in a downstream velocity decrease in the upper portion of the mixed layer and an increase in the lower portion of the mixed layer to the west of the stream core where velocity shears are positive and vice versa at locations where velocity shears are negative. Furthermore, the downstream velocity near the surface decreases mainly because of the southward Ekman flow induced by the strong westerlies during the cold air outbreak.

It is interesting that the modifications of the Gulf Stream are not uniform in the downstream direction even though the forcings are (Fig. 9). The largest SST changes occur near the temperature fronts. In the cooling experiment, the stream is cooled considerably in regions where the heat lost from the ocean to the atmosphere is the greatest (around the open triangle), with the warm filaments being cooled even more. The decrease in surface velocity just to the left of the stream core and the increase to the right of the core are due to mixing of momentum in the vertical. However, the southward velocity in the warm filament appears to be intensified, suggesting a possible interaction between the motions associated with meanders and the heat-flux-forced motions. 
(a)

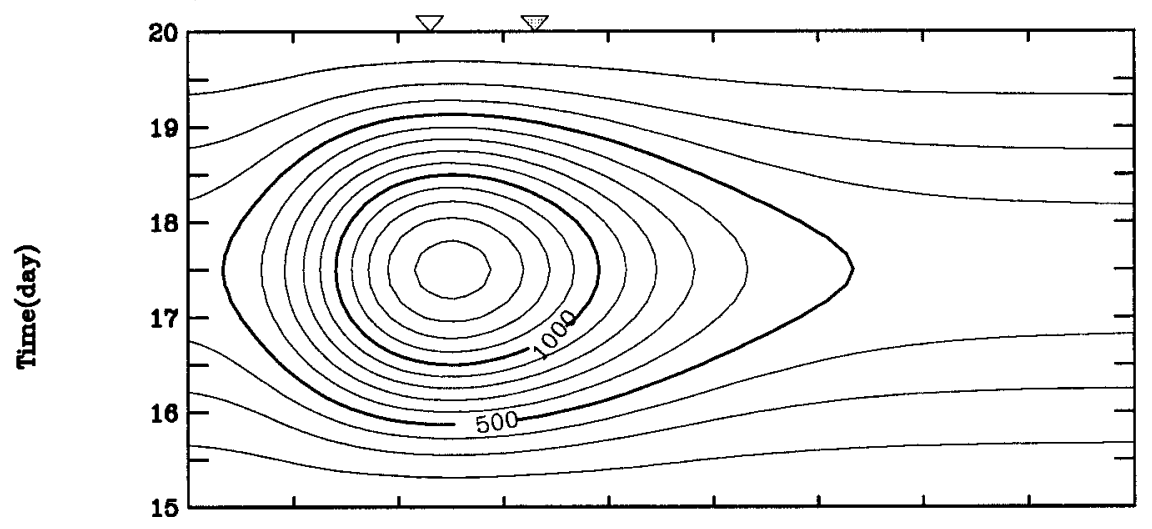

(b)

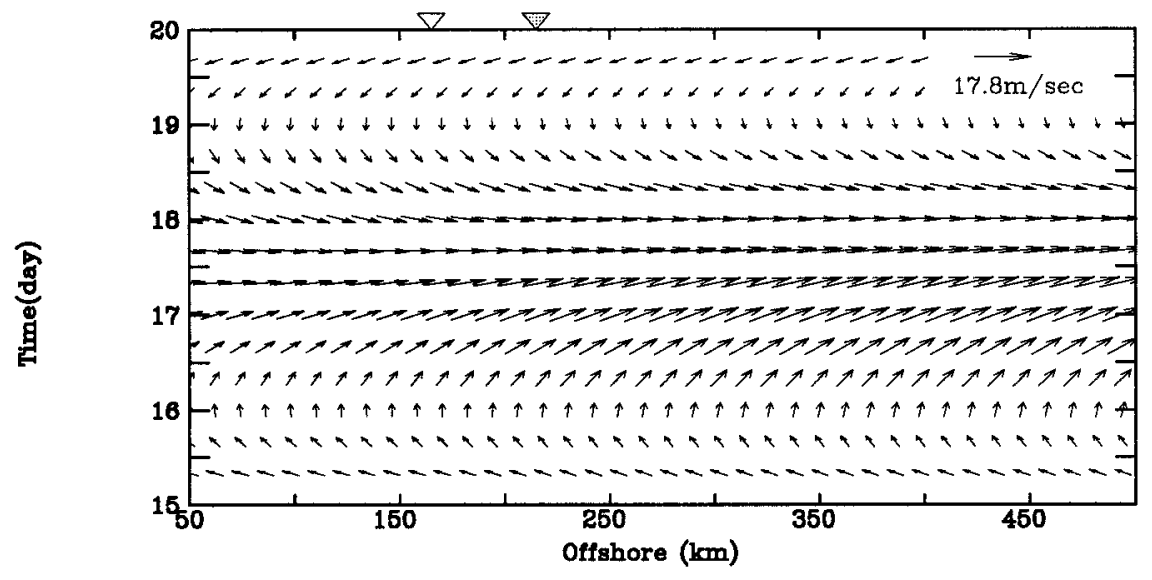

FIG. 6. Total heat flux (a) and the wind (b) imposed on the sea surface in the model to simulate atmospheric forcing during a severe winter storm [adapted from Xue et al. (1995)].

Temperature changes in the wind experiment (Fig. 9b) are distinctively different. Temperature decreases near the shoreward side of the stream, whereas it increases near the seaward side of the stream, indicating that the stream has been moved offshore by the southerly winds during the first half of the storm cycle. At day 18 the velocity responds to the westerly winds by generating southward flow anomalies at most places. The southward Ekman flow in general is stronger offshore because the wind becomes increasingly strong offshore. However, it increases noticeably when crossing to the shoreward side of the Gulf Stream front. Note also the intensified southward flows in the warm filaments. Transverse velocities are large near the coast, suggesting strong wind-induced upwelling or downwelling. They are strong also on the anticyclonic shear side of the stream and appear to form clockwise circulations. These clockwise circulations, collocating with the troughs of the meanders on the seaward side of the Gulf Stream front, tend to make these meanders less unstable.

The response to combined heat flux and wind forcing can be found in the combined experiment (Fig. 9c). This forcing results in even greater decreases in temperature along the shoreward side of the Gulf Stream, but less temperature changes along the seaward side. The clockwise circulations stand out clearly from a background of weaker southward flows. The difference between the combined experiment and the linear combination of the cooling and the wind experiment is larger around the seaward side of the stream, suggesting stronger nonlinear interactions there.

To elucidate how meanders are modified during the storm event, Fig. 10 shows the surface temperature anomaly, which is the difference between the temperature and its downstream average, for the four experiments. In the unforced experiment the surface temperature anomaly clearly shows a side-by-side meander pattern along both sides of the Gulf Stream. On the shoreward side, meander troughs correspond to the well-defined cold anomalies and meander crests correspond to the warm anomalies. However, warm anomalies also trail the meander crests and wrap around the 

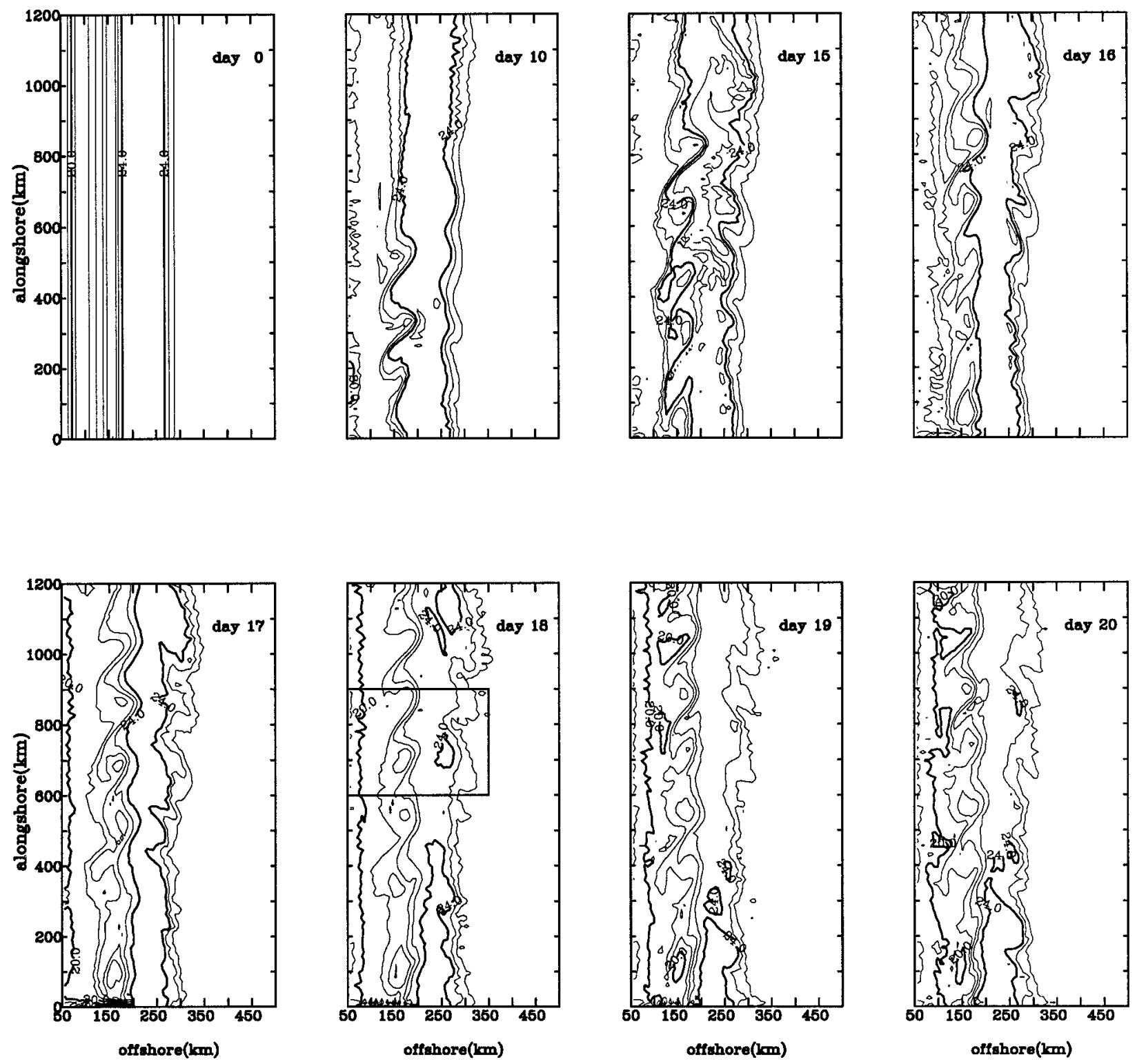

FIG. 7. As in Fig. 3 except for the combined experiment.

meander troughs on the shoreward side to form a backward breaking pattern. Similarly, on the seaward side there exists a pattern of alternative positive (crest) and negative (trough) anomalies. A backward breaking pattern at the leading portion of the troughs is also apparent, with warm Gulf Stream water trailing behind on the Sargasso Sea side. Meanders on the two sides of the Gulf Stream are almost $180^{\circ}$ out of phase and have comparable amplitudes at the surface. Figures 3 and 7 suggest that they also have comparable wavelengths, unlike the unstable modes of Xue and Mellor (1993), in which the seaward side meander patterns are shorter. In fact, the wavelength of the seaward side meander patterns found in the present study agree with the linear stability analysis of Xue and Mellor, whereas the wave- length of the shoreward side meanders is smaller. This is likely due to the different stream configurations used in the two studies. The stream configuration used in Xue and Mellor (1993) was derived from an analytical form, whereas the one used in this study contains an observed temperature distribution in the top $350 \mathrm{~m}$. Second, Xue and Mellor (1993) was a linear stability study assuming a wave form of disturbances in the downstream direction that would be similar to applying periodic boundary conditions in the present study. Experiments with periodic boundary condition and experiments with sponge layers have been performed to minimize boundary effects on the interior solution, thus leading us to believe that the characteristics of the modeled meanders are inherited from the stream configuration, instead of the 

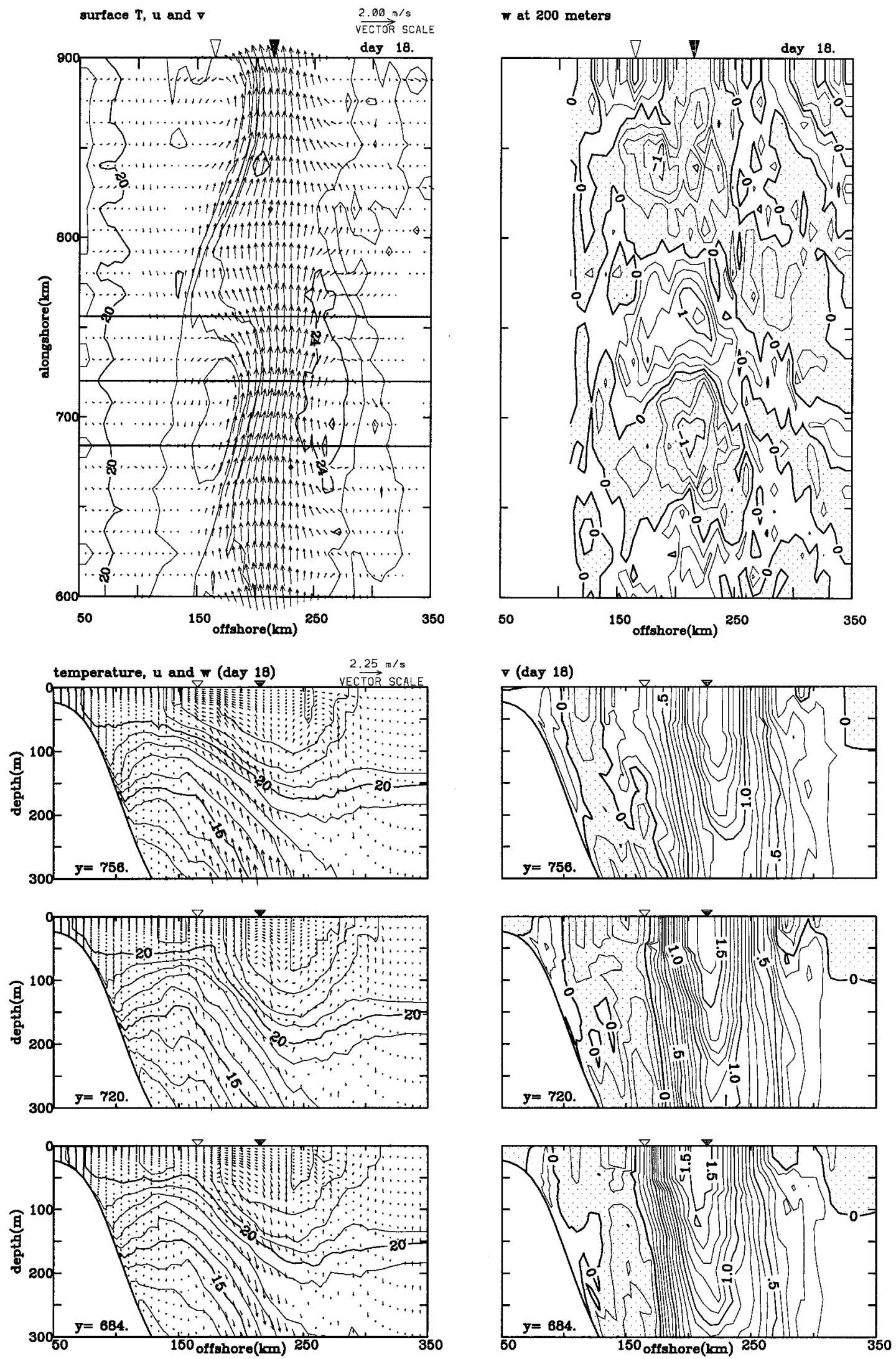

FIG. 8. As in Fig. 4 except for the combined experiment. Day 18 corresponds to the time immediately after the cold air outbreak. 

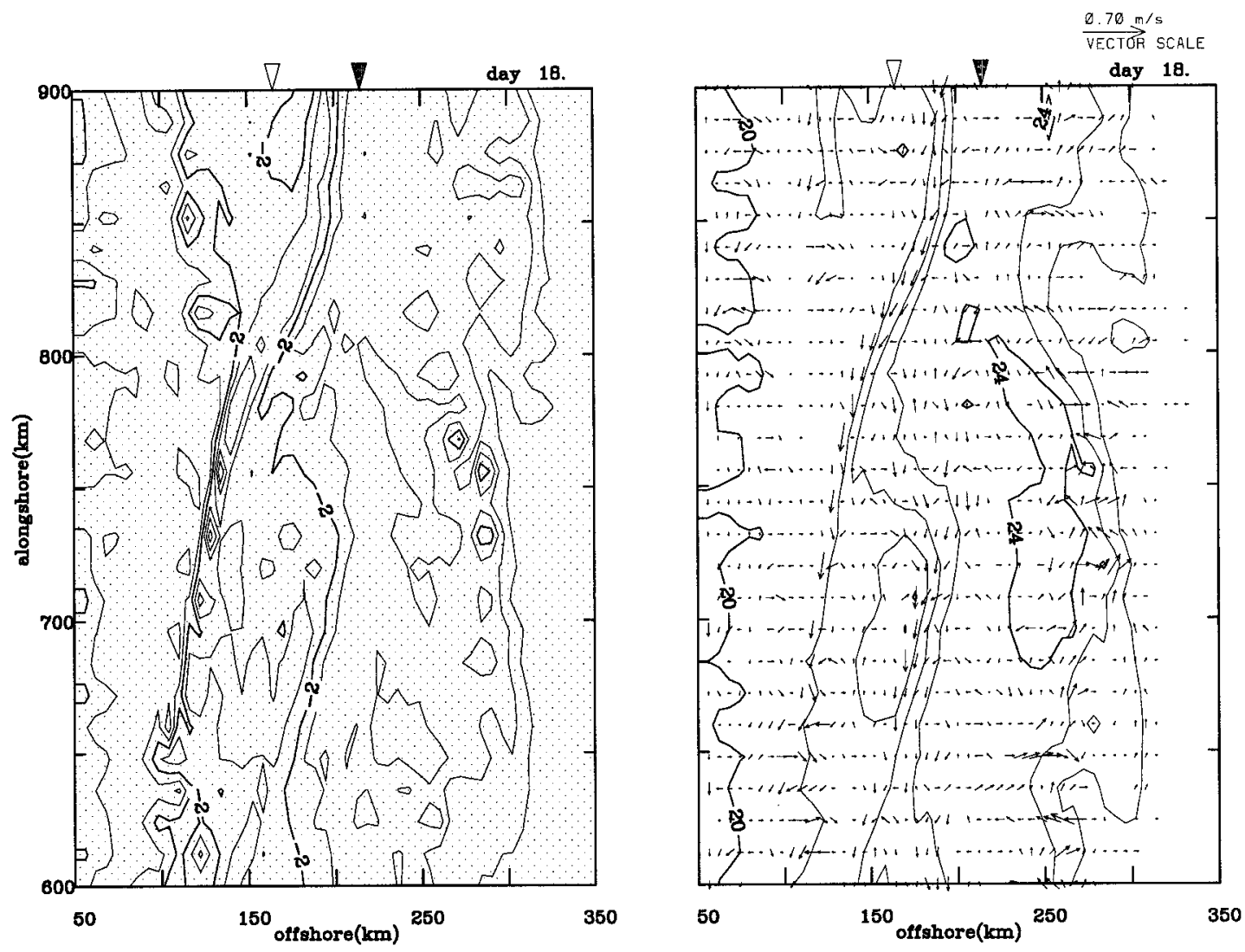

FIG. 9. Changes of temperature (left panels) and horizontal velocity (right panels) at the surface: (a) cooling-no forcing, (b) wind-no forcing, and (c) combined-no forcing. Also shown in the right panels are the surface temperature from the cooling, wind, and combined experiment, respectively. Contour interval is $1^{\circ} \mathrm{C}$.

artifact of the open boundary conditions used in the model.

Cooling has relatively strong effects on the warm filaments on both sides of the stream. Additionally, the temperature anomaly is generally negative around the core of the stream. It should be noted that the area depicted in Fig. 10 is within the northern half of the domain. Since the water is continuously cooled after entering the domain, the northern half of the domain is always cooler than the southern half (Fig. 7), and this results in the cold anomaly around the core in Figs. 10b and $10 \mathrm{~d}$ after subtracting the downstream average. Wind effects on the shoreward side meanders are relatively small. However, as winds become stronger, they have strong effects on the offshore meanders. The southerly winds during the first half of the storm event generate eastward flows that advect the seaward front and meanders offshore. Furthermore, strong westerlies during the cold air outbreak phase generate southward Ekman flows that seem to slow the downstream propagation of the seaward side meanders. With both the heat flux and the wind operating simultaneously, the shoreward side meanders in the combined experiment are little affected, except for the weakening of the warm filaments. However, the meander amplitudes on the seaward side are significantly reduced and their propagation speed is slower because of the southward flows generated by the strong westerlies.

\section{Discussion}

Momentum, energy, and heat budgets have been calculated using the model results. The momentum budget is useful in examining how the momentum input by the wind redistributes within the mixed layer and within the Gulf Stream and where it is eventually lost to diffusion. The important dynamic balances in different regions (e.g., the mixed layer, the front, and the deeper ocean) can be elucidated by comparing magnitudes of the various acceleration terms in the momentum equations. The energy budget can reveal the mechanisms of meander growth and thereby help to assess the atmospheric influences on meander characteristics. The heat budget is of interest because it reveals the processes that supply the vigorous, ocean-to-atmosphere heat flux during a cold air outbreak.

\section{a. Momentum}

As expected, the geostrophic balance dominates in the cross-stream direction (Fig. 11). Among the smaller 

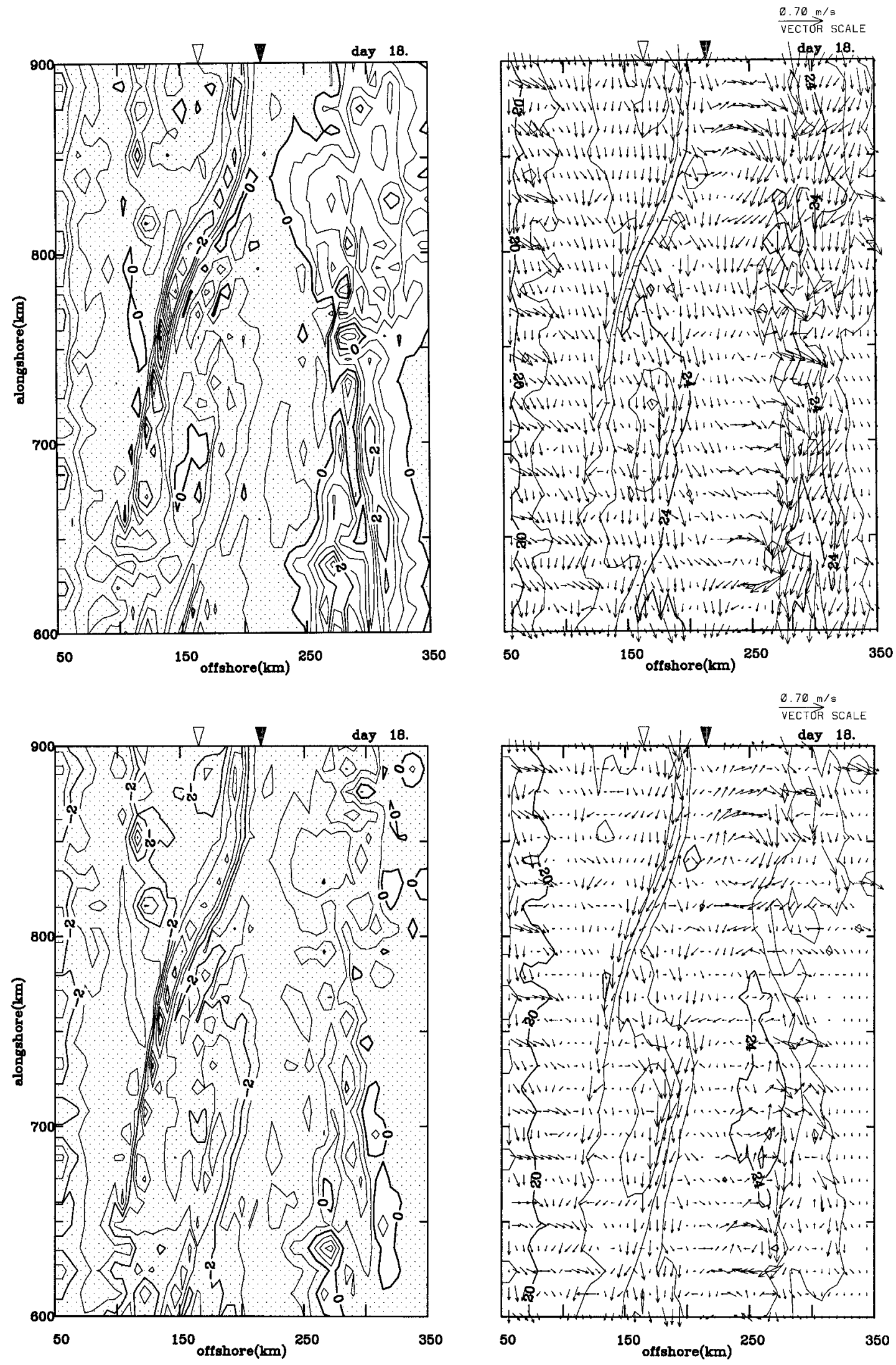

FIG. 9. (Continued) 
(a) no forcing

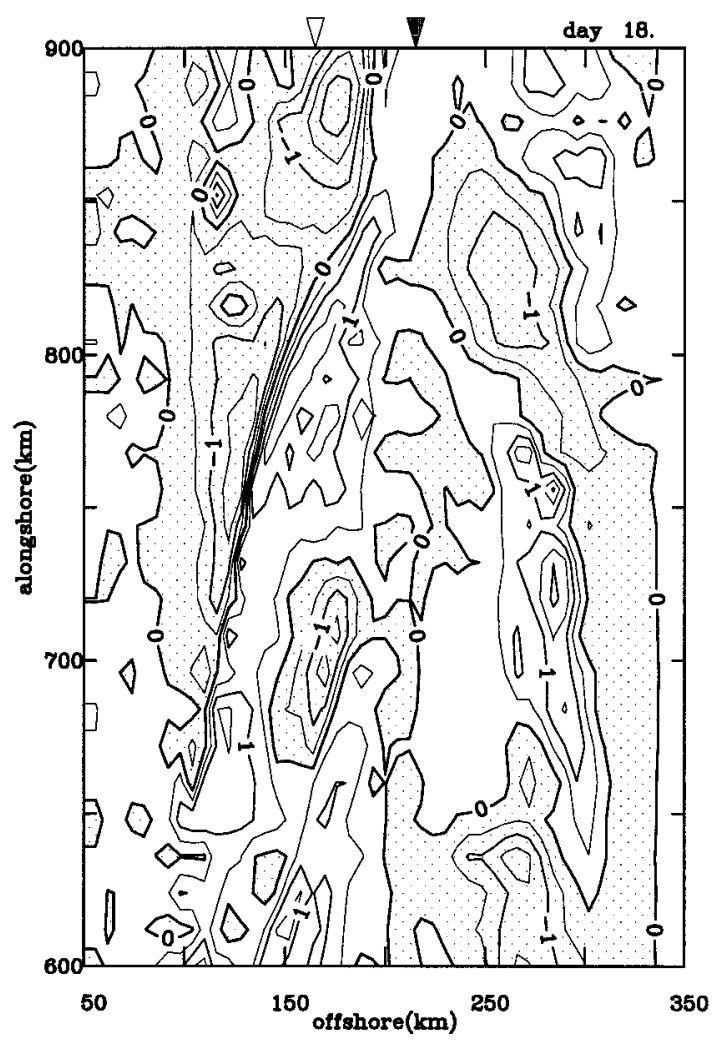

(c) wind

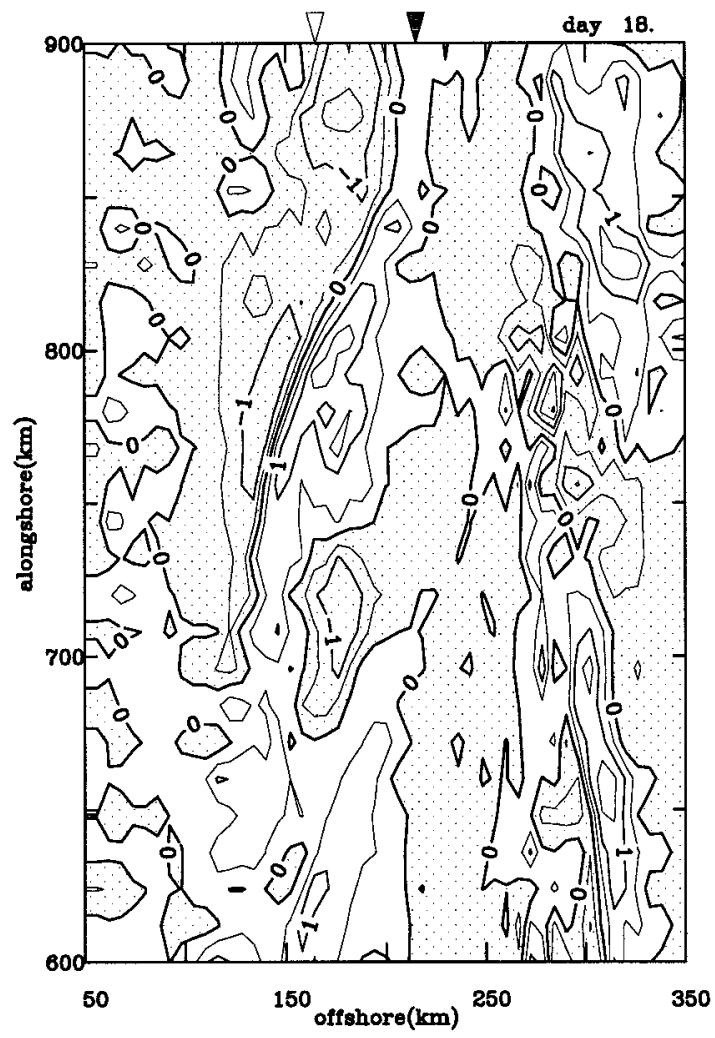

(b) cooling

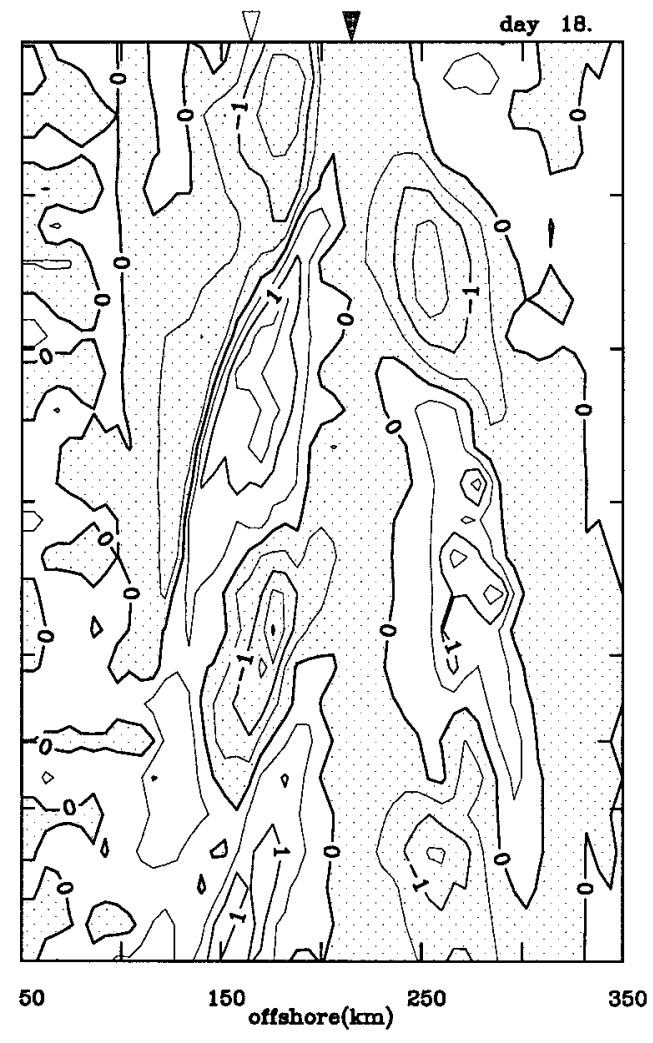

(d) combined

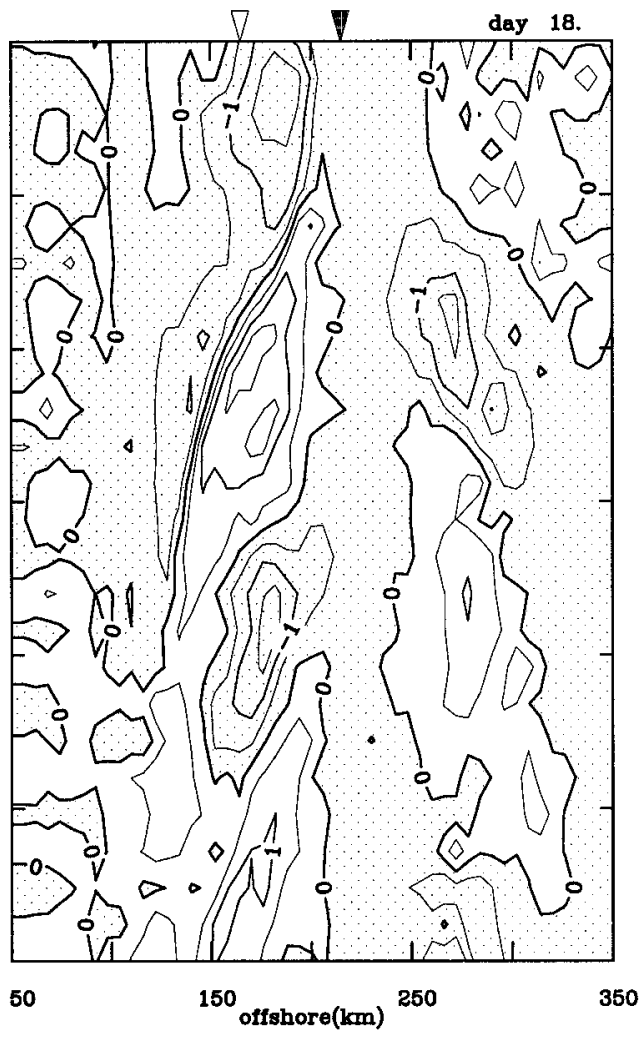


terms, the nonlinear advection term is the largest, although still less than $20 \%$ of the Coriolis term. In comparison, nonlinear advection in the downstream direction is smaller than the Coriolis term by only a factor of 2 . In both directions nonlinear effects become important at the locations of backward breaking, where $\partial u / \partial y$ and $\partial v / \partial y$ are large. Horizontal diffusion is generally small, about two orders of magnitude smaller than the advection term, hence not shown. Vertical diffusion is also an order of magnitude smaller than the advection term in the unforced experiment. However, during cold air outbreaks, both severe cooling and strong winds enhance vertical mixing, resulting in small increases of the vertical diffusion term in the cooling experiment (which is not shown). Figure $11 \mathrm{~b}$ shows that in the experiment forced by winds, vertical diffusion at the surface increases to about one-third of the Coriolis term, significantly affecting the nearly geostrophic balance in the cross-stream direction. The Coriolis term, the pressure gradient term, and the vertical diffusion term form the near-Ekman balance, more so offshore where winds are the strongest. Contributions from the nonlinear advection remain small at less than $20 \%$ of the Coriolis term. Moreover, cross-sectional distributions of individual terms in Fig. 12 show the momentum input by the wind is dissipated rather quickly within a thin mixed layer, which varies from about $20 \mathrm{~m}$ on the shoreward side to about $50 \mathrm{~m}$ on the seaward side. A near-geostrophic balance remains below the mixed layer.

\section{b. Energy}

Model results (Fig. 10) seem to suggest that meanders on the shoreward side of the stream are affected little by atmospheric forcing, whereas those on the seaward side might be significantly affected. The energy budget of the mean flow and eddies in each of the four numerical experiments can reveal the mechanisms for meander growth. Following Xue (1991), four energy components and two conversion terms are defined as follows

the mean available potential energy $\left(P_{m}\right)$ :

$$
\frac{g \overline{\tilde{\rho}}^{2}}{2 \rho_{o}\left(-\partial \rho_{b} / \partial z\right)}
$$

the eddy potential energy $\left(P_{e}\right)$ :

$$
\frac{g \overline{\tilde{\rho}^{\prime 2}}}{2 \rho_{o}\left(-\partial \rho_{b} / \partial z\right)}
$$

the kinetic energy of the mean flow $\left(K_{m}\right)$ :

$$
\frac{\bar{u}^{2}+\bar{v}^{2}}{2}
$$

the eddy kinetic energy $\left(K_{e}\right)$ :

$$
\frac{\overline{u^{\prime 2}+v^{\prime 2}}}{2}
$$

the barotropic conversion $\left(K_{m} \rightarrow K_{e}\right)$ :

$$
-\left(\overline{u^{\prime} u^{\prime}} \frac{\partial \bar{u}}{\partial x}+\overline{u^{\prime} w^{\prime}} \frac{\partial \bar{u}}{\partial z}+\overline{u^{\prime} v^{\prime}} \frac{\partial \bar{v}}{\partial x}+\overline{v^{\prime} w^{\prime}} \frac{\partial \bar{v}}{\partial z}\right)
$$

and the baroclinic conversion $\left(P_{m} \rightarrow P_{e}\right)$ :

$$
-\frac{g}{\rho_{o}\left(-\partial \rho_{b} / \partial z\right)}\left(\overline{u^{\prime} \tilde{\rho}^{\prime}} \frac{\partial \overline{\tilde{\rho}}}{\partial x}+\overline{w^{\prime} \tilde{\rho}^{\prime}} \frac{\partial \overline{\tilde{\rho}}}{\partial z}\right),
$$

where $\rho_{b}(z)$ is a background density profile defined for an ocean at rest (which in the present calculation is taken as the density at the eastern boundary of the domain); $p_{b}(z)$ is the associated hydrostatic pressure that satisfies

$$
\begin{aligned}
\partial p_{b} / \partial z & =-\rho_{b} g ; \\
\tilde{\rho}(x, y, z, t) & =\rho(x, y, z, t)-\rho_{b}(z) ; \quad \text { and } \\
\tilde{p}(x, y, z, t) & =p(x, y, z, t)-p_{b}(z),
\end{aligned}
$$

which satisfy $\partial \tilde{p} / \partial z=-\tilde{\rho} g$. Overbars denote the average in the downstream direction over the whole domain. It should be noted that the positive barotropic (baroclinic) conversion at one location does not necessarily increase $K_{e}\left(P_{e}\right)$ there because of nonzero energy fluxes and pressure work. However, positive $K_{m} \rightarrow K_{e}\left(P_{m} \rightarrow P_{e}\right)$ does imply that part of $K_{m}\left(P_{m}\right)$ is converted to $K_{e}\left(P_{e}\right)$.

First, we identify mechanisms of meander growth in the unforced experiment. Figure 13 shows the time evolution of the four energy components in this experiment. Meanders grow largely at the expense of available potential energy in the Gulf Stream. Figure 13 also shows that on the domain average meanders stop growing around day 12. Although meanders gradually emerge in the northern half of the domain, some in the southern half of the domain actually lose strength as seen in Fig. 3. Nevertheless, the initiation of the atmospheric forcing at day 15 results in modifications to fully developed meanders.

Cross-sectional distributions of $K_{e}$ and $P_{e}$ in Fig. 14 show that there are two primary regions of eddy activity: one on the shoreward side of the stream (centered at the open triangle) and another on the seaward side of the Gulf Stream front (centered at about $300 \mathrm{~km}$ offshore). The shoreward side eddies have a much larger vertical scale extending from the surface to the seafloor,

FIG. 10. Surface temperature anomaly (the temperature subtracting its downstream average) for the unforced experiment (a), the cooling experiment (b), the wind experiment (c), and the combined experiment (d). 

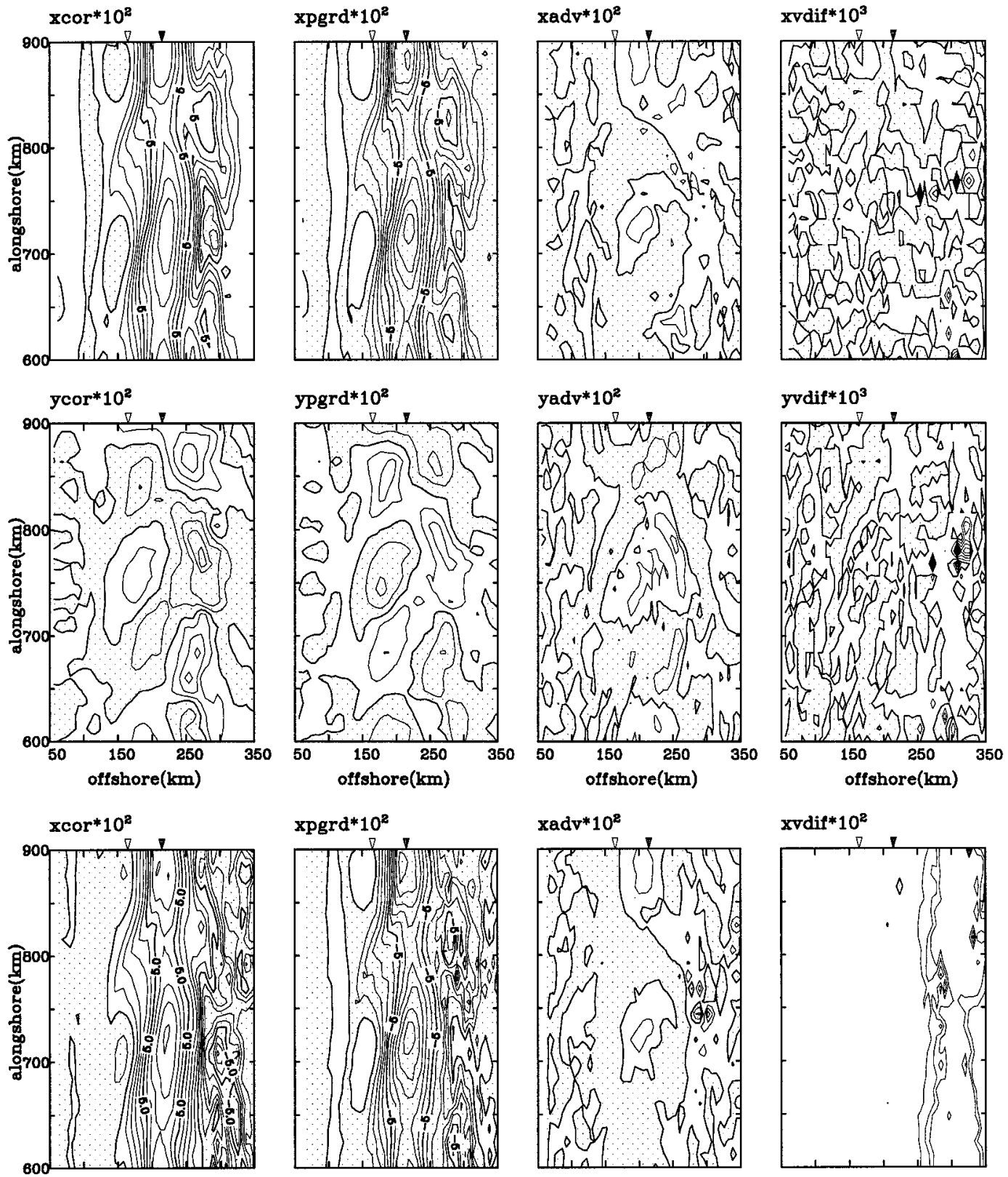

xvdif*10
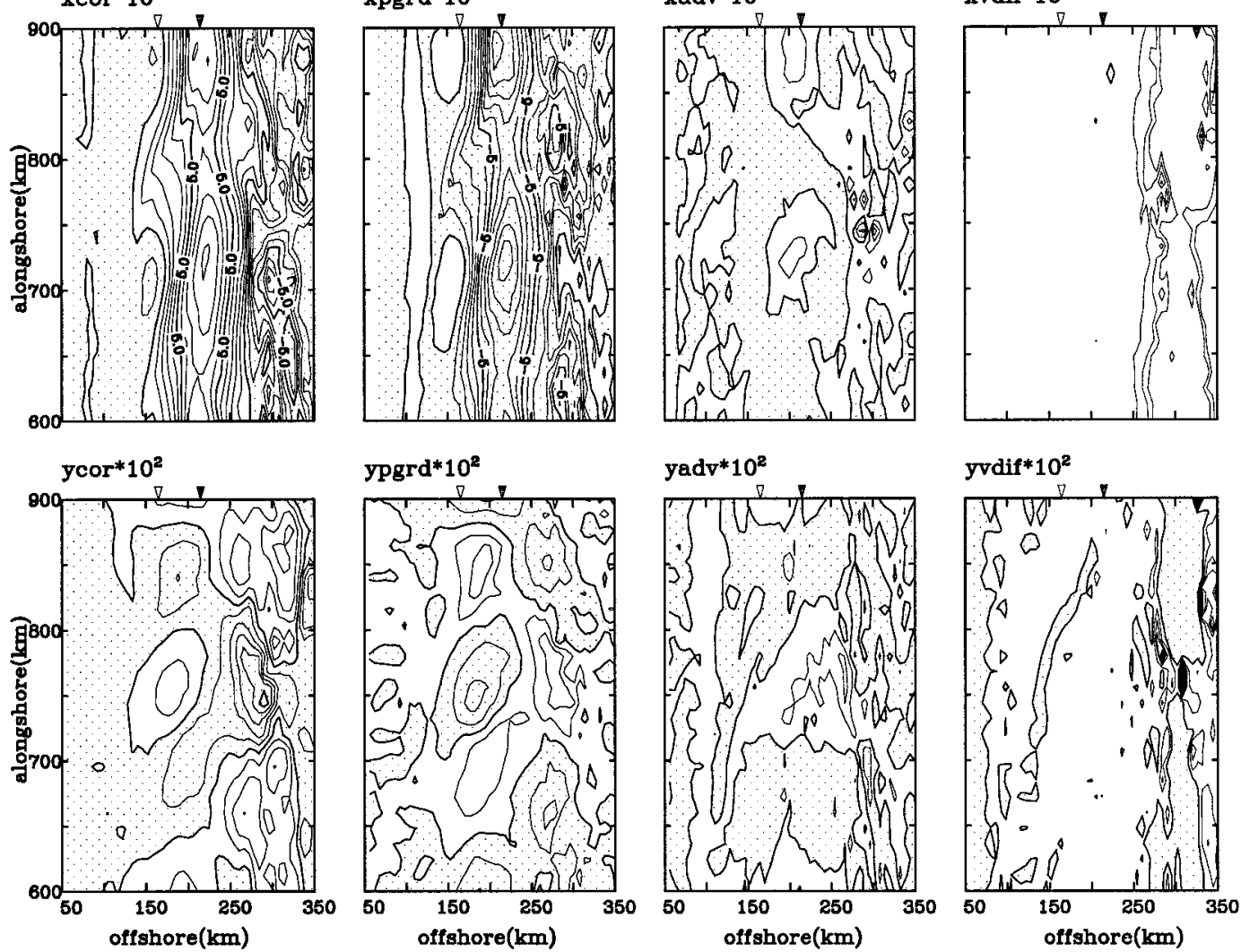

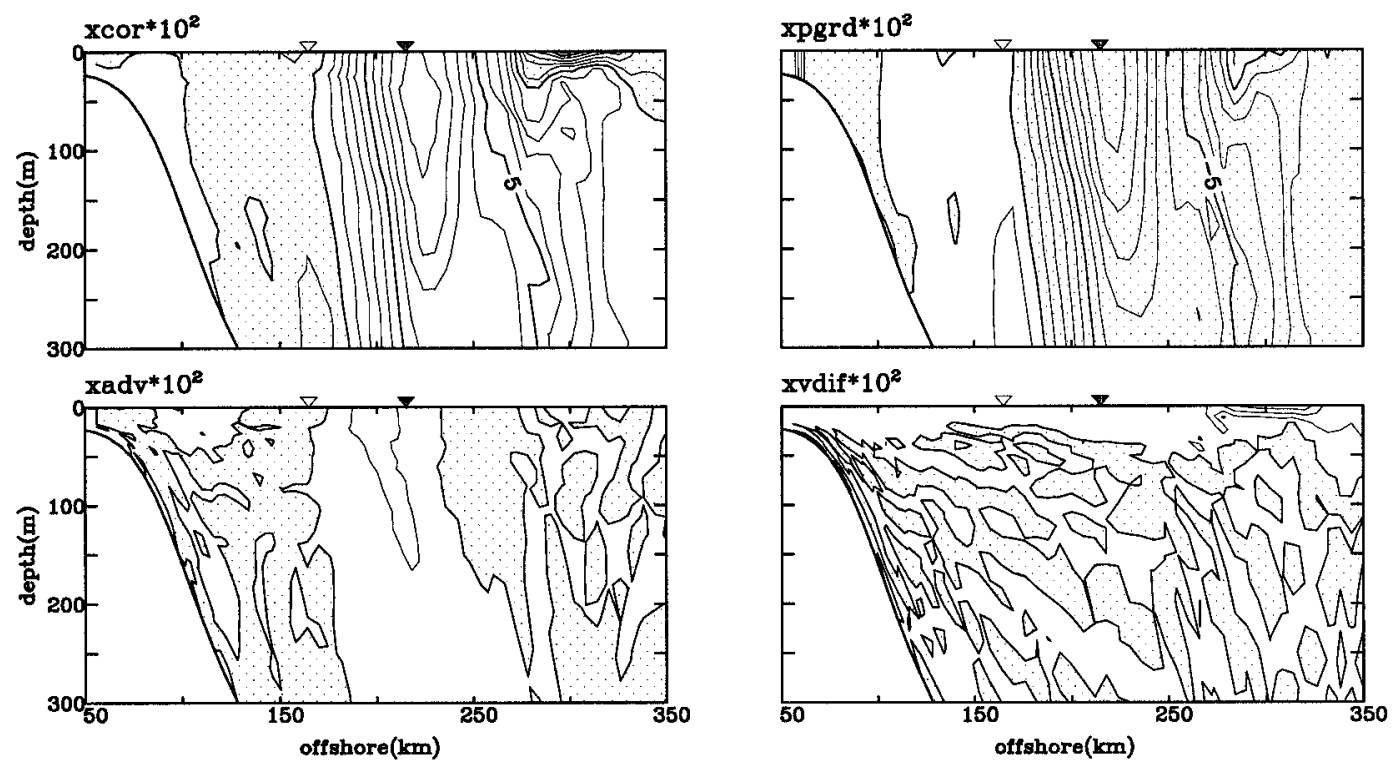

FIG. 12. Cross-sectional distributions of the forcing terms in the $x$-momentum equations for the wind experiment on day 18.

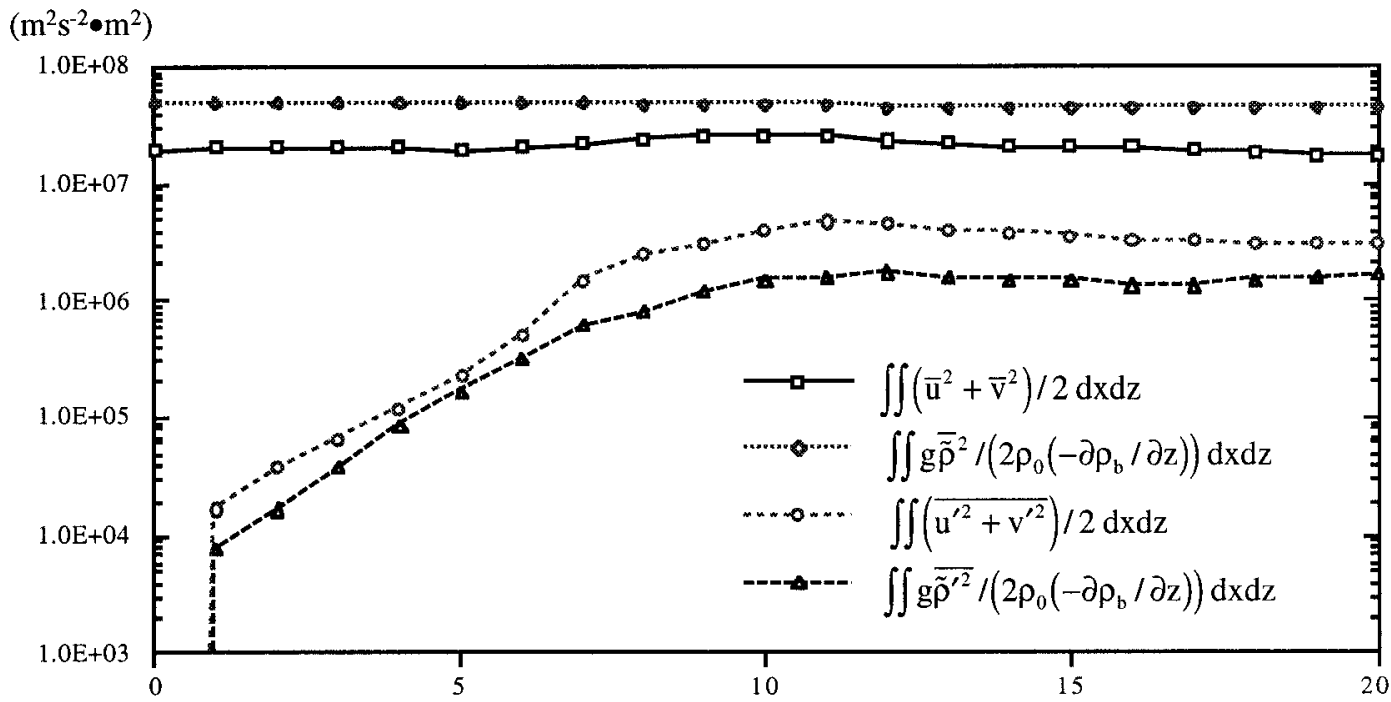

time (day)

FIG. 13. Time variations of the downstream-averaged and cross-sectional-integrated $K_{m}$ (kinetic energy of the mean flow), $P_{m}$ (available potential energy of the mean flow), $K_{e}$ (eddy kinetic energy), and $P_{e}$ (eddy potential energy) in the unforced experiment.

$\leftarrow$

FIG. 11. Surface distributions of various forcing terms in the momentum equations for the unforced experiment (a) and the wind experiment (b) on day 18. All the terms have been moved to the right-hand side of the equations. 

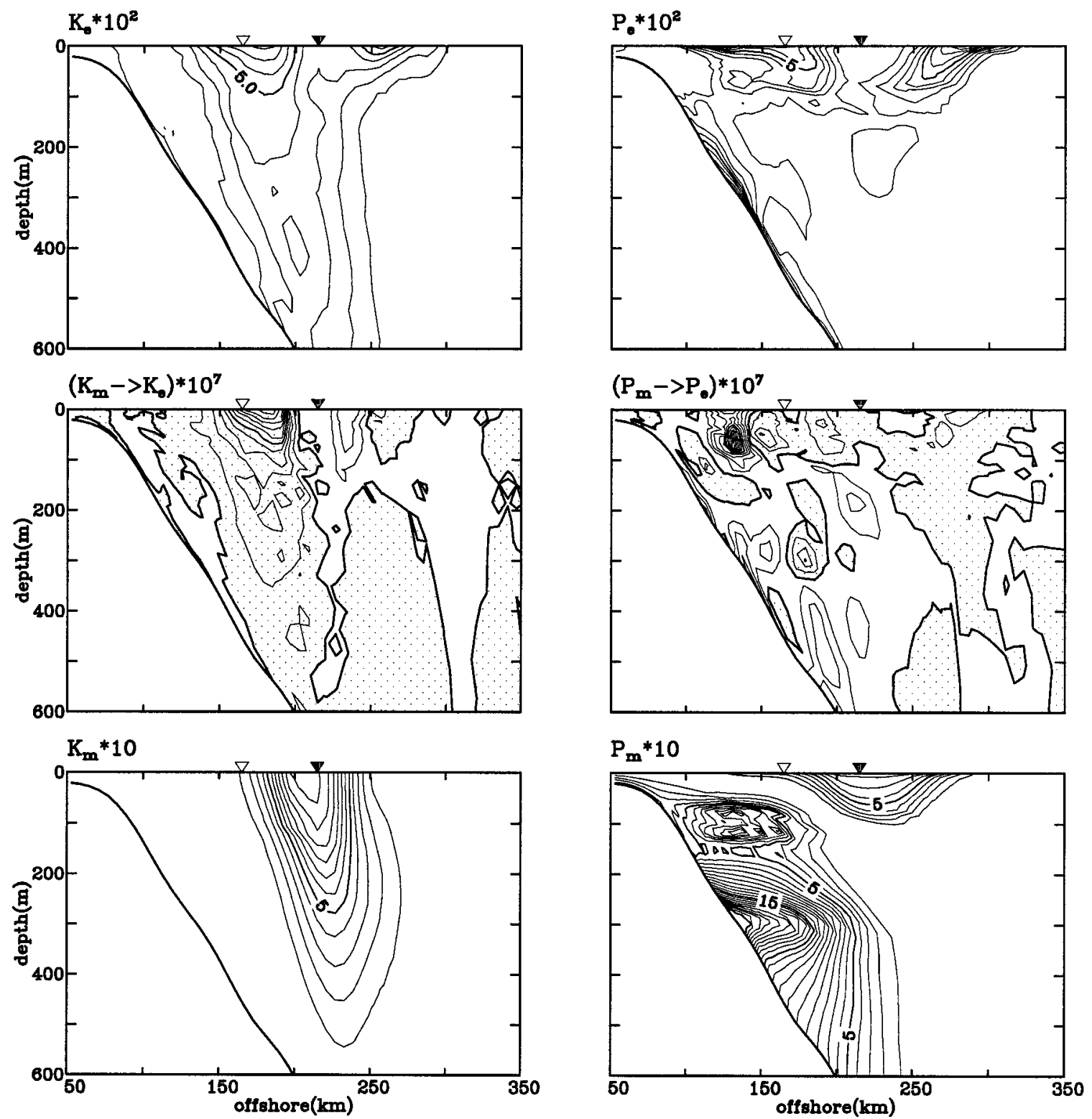

FIG. 14. Energy partitions on day 18 in the unforced experiment. Top panels are the distributions of $K_{e}$ and $P_{e}$, scaled by $0.01 \mathrm{~m}^{2} \mathrm{~s}^{-2}$. Middle panels are the distributions of the barotropic energy conversion $\left(K_{m} \rightarrow K_{e}\right)$ and the baroclinic energy conversion $\left(P_{m} \rightarrow P_{e}\right)$, scaled by $10^{-7} \mathrm{~m}^{2} \mathrm{~s}^{-2} \mathrm{~s}^{-1}$. Bottom panels are the distributions of $\mathrm{K}_{\mathrm{m}}$ and $\mathrm{P}_{\mathrm{m}}$, scaled by $0.1 \mathrm{~m}^{2} \mathrm{~s}^{-2}$. Contour interval is 1 .

which is about $500-600 \mathrm{~m}$ deep at this location. The seaward side eddies are much shallower features extending only to about $100 \mathrm{~m}$. Energy conversion terms in Fig. 14 show rather distinct mechanisms at these two locations. The shoreward side meanders are barotropically stable; baroclinic instability is the sole mechanism for their growth. In contrast, the seaward side meanders grow primarily because of barotropic instability with very little contribution from baroclinic instability.

These findings are consistent with the linear instability analyses of Xue and Mellor (1993). Their deep shoreward side meanders [the $m_{1}$ mode in Xue and Mellor (1993)] are essentially a Charney-Eady unstable mode. Although this mode is barotropically unstable in

FIG. 15. Changes in $K_{m}$ (a), $P_{m}$ (b), $K_{e}$ (c), and $P_{e}$ (d) on day 18 due to the heat flux (top panels), the wind (middle panels), and the combination of the heat flux and the wind (bottom panels). $K_{m}$ and $P_{m}$ are scaled by $0.1 \mathrm{~m}^{2} \mathrm{~s}^{-2} ; K_{e}$ and $P_{e}$ are scaled by $0.01 \mathrm{~m}^{2} \mathrm{~s}^{-2}$. Contour interval is 0.5 . 
(a) $\mathrm{K}_{\mathrm{m}} * 10$
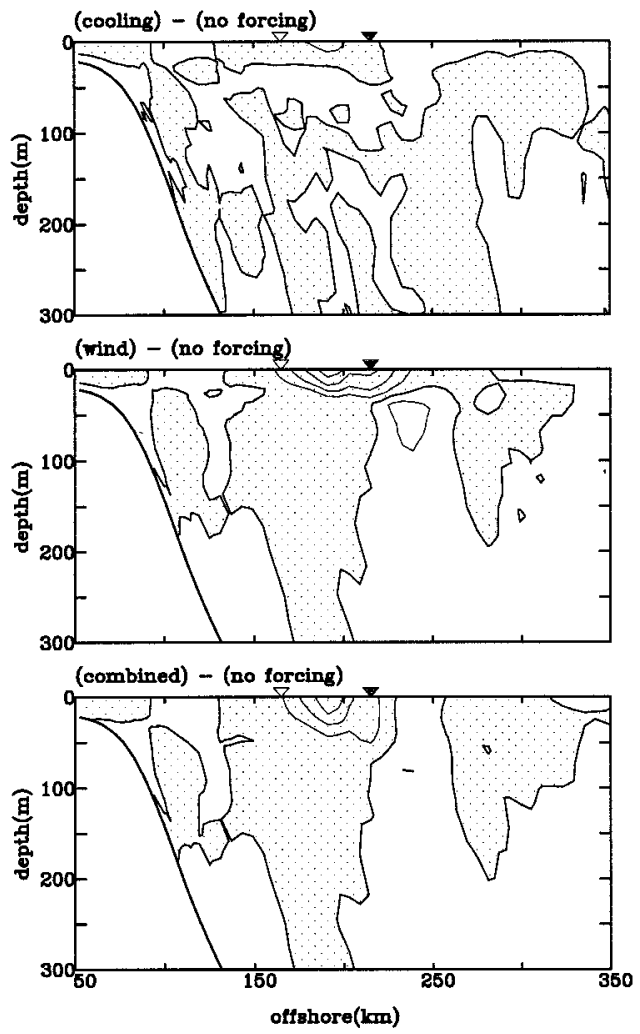

(c) $\mathrm{K}_{\bullet} * 10^{2}$
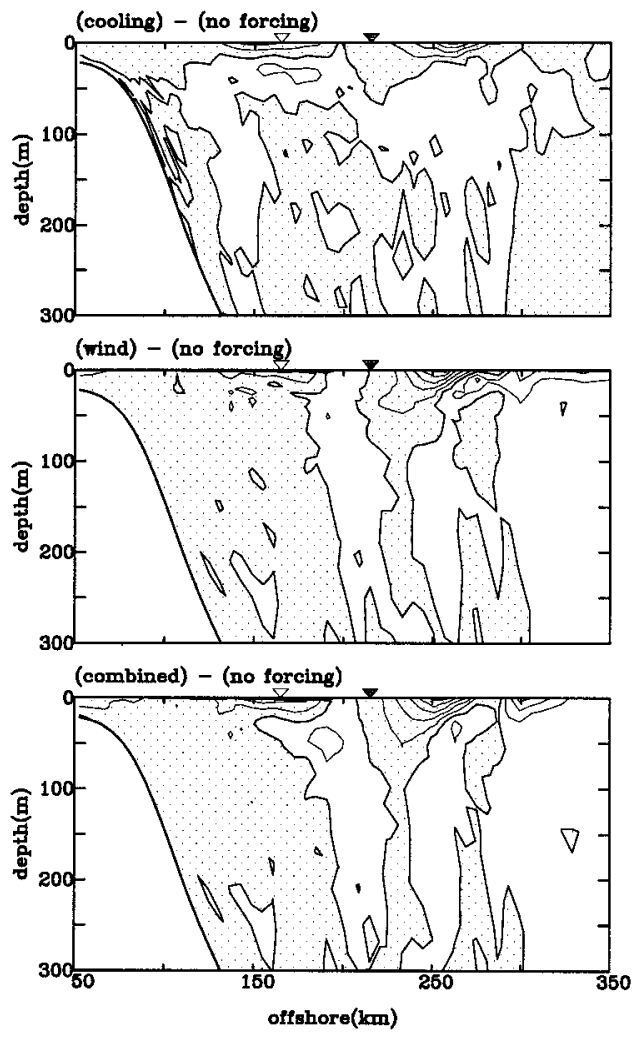

(b) $P_{m} * 10$
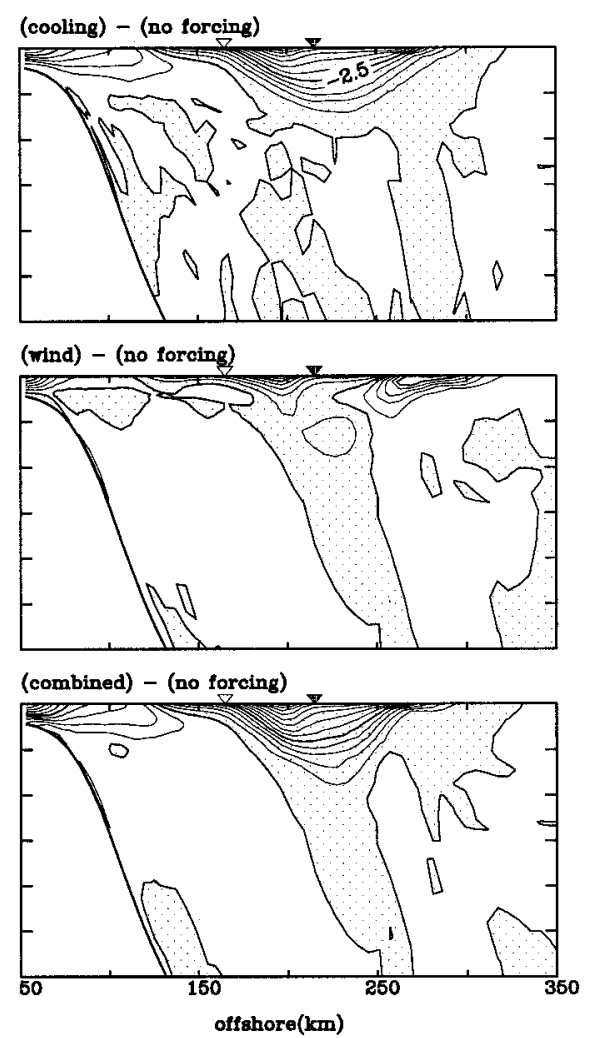

(d) $P_{\bullet} * 10^{2}$
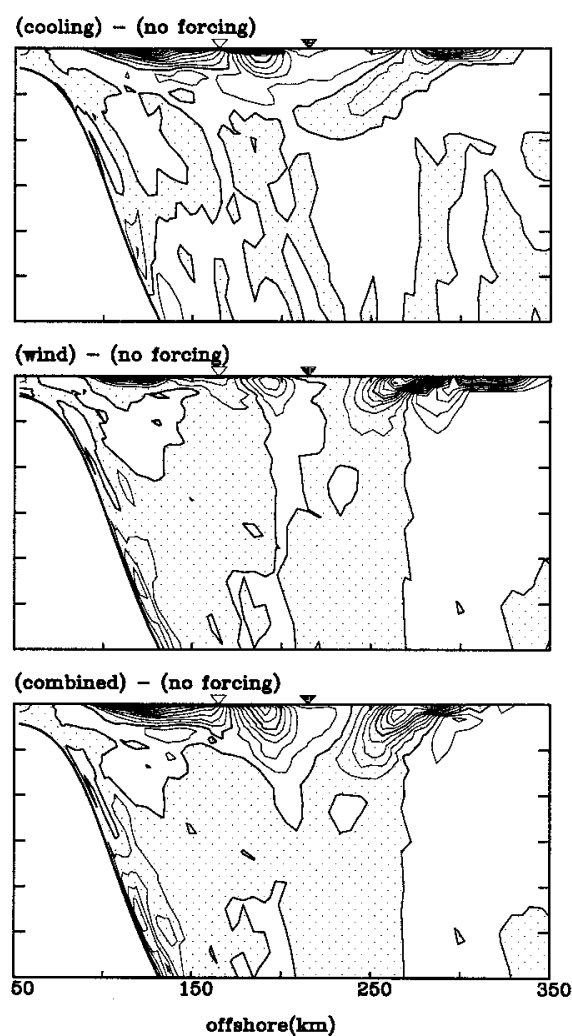
(a) before cooling

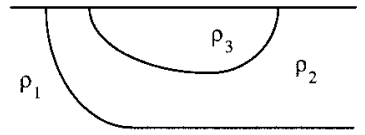

FIG. 16. A schematic on density structures in the upper Gulf Stream before (a) and after (b) cooling taking place. $\rho_{1}$ represents the density of the shelf water; $\rho_{2}$ represents the density in the Sargasso Sea; $\rho_{3}$ represents the density of the surface Gulf Stream water. After cooling, their counterparts are $\rho_{1}^{\prime}, \rho_{3}^{\prime}$, and $\rho_{3}^{\prime}$, respectively.

the linear regime, fully developed, strongly nonlinear meanders tend to be barotropically stable (Dewar and Bane 1985; Lee et al. 1991). The shallower seaward meanders [the $m_{2}$ mode in Xue and Mellor (1993)] emerge when inertial critical levels fall inside the domain so that the Eady neutral mode coalesces with the neutral inertial-gravity wave and results in weak growth (Nakamura 1988). However, horizontal gradients of the downstream velocity favor barotropic instability there.

Further explanation of meander growth along two sides of the Gulf Stream can be found in the distributions of $K_{m}$ and $P_{m}$, which are the energy sources for meander growth. The $K_{m}$ is concentrated at the core of the stream (centered at the solid triangle) with a single maximum at the surface, whereas $P_{m}$ has several local maxima. The largest is next to the inner slope. The tilted thermocline forms a subsurface front adjacent to the inner slope from 200-m depth down to $600 \mathrm{~m}$, as seen in Fig. 2 . This subsurface front stores a great amount of available potential energy. The local maximum of the $P_{m}$ at $100 \mathrm{~m}$ reflects the cold water dome in the particular configuration of the Gulf Stream being used. The combination of these two forms the primary energy source for the shoreward side meanders. The fact that the $P_{m}$ has this subsurface maximum results in a large vertical scale for this mode. On the seaward side, the energy source is dominated by the $K_{m}$, which supports barotropic instability. However, there also exists a weak surface maximum of $P_{m}$ at this location, and this results in weak baroclinic conversion of energy offshore, as seen in $P_{m} \rightarrow P_{e}$. Seaward side meanders are thus boundarytrapped, because there both the $K_{m}$ and the $P_{m}$ are concentrated at the surface. Therefore, they are potentially more vulnerable to the surface forcing.

Figures 15a and 15b show changes of $K_{m}$ and $P_{m}$ in response to the imposed heat flux and winds, respectively. Cooling enhances vertical mixing, and that results in the decrease of the downstream velocity at the surface and the increase immediately below on the cyclonic shear side of the stream (where $\partial v / \partial z$ is positive in the upper water column) and vise versa on the anticyclonic shear side (where $\partial v / \partial z$ is negative in the upper water column). Similarly, the $K_{m}$ decreases where the downstream velocity decreases, and it increases where the downstream velocity increases. Nevertheless, the changes in $K_{m}$ due to cooling are less than $10 \%$. Effects of cooling are far greater in the $P_{m}$, which is

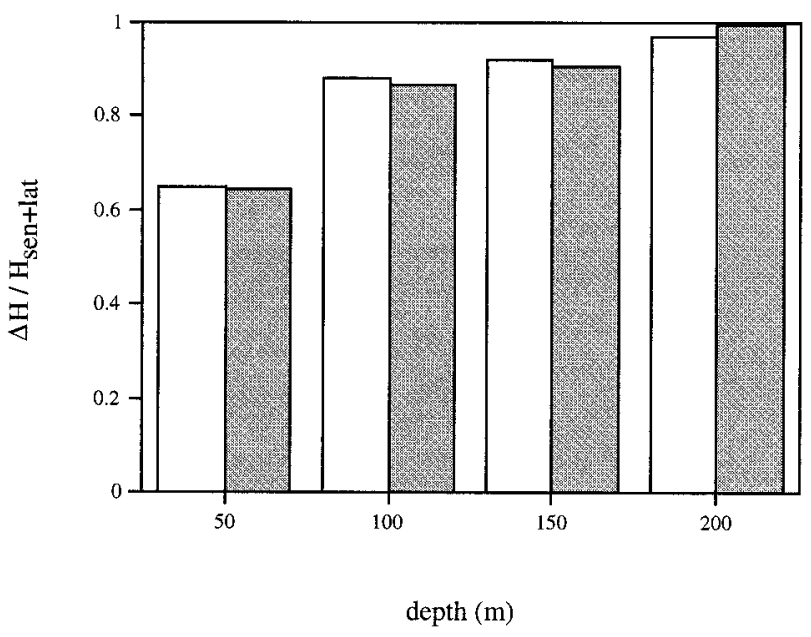

FIG. 17. The ratio between the change of heat content in a control volume whose base is defined by the horizontal ordinal and the heat release from the ocean to the atmosphere as the sum of latent heat and sensible heat. $\square$ represents the results in whole domain; $\square$ represents the results in the Gulf Stream.

reduced by two-thirds at the surface. Although the surface is cooled everywhere in the cooling experiment (Fig. 9a), the $P_{m}$ at the surface increases only near the coast and decreases elsewhere. The decrease in temperature generally implies cold waters being lifted, thereby increasing potential energy. However, in the case of surface cooling, temperature decrease at the surface due to the release of internal energy (heat) makes the surface water heavier than the water immediately below, and thus it sinks. When the surface water sinks, the water immediately below rises. If this water is heavier than the reference water at the same depth, available potential energy could increase. If this water is lighter than the reference water at the same depth, the effect of the sinking surface water dominates and available potential energy increases. The schematic diagram in Fig. 16 illustrates these changes in the $P_{m}$ in response to the surface cooling. Before cooling, $\rho_{1}>\rho_{2}>\rho_{3}$. During a cold air outbreak, maximum cooling occurs in the Gulf Stream $\left(\rho_{3}\right)$, some cooling occurs in the shelf water $\left(\rho_{1}\right)$, and minimal changes farther offshore $\left(\rho_{2}\right)$. After cooling, $\rho_{2}=\rho_{2}^{\prime}, \rho_{1}^{\prime}-\rho_{2}^{\prime}>\rho_{1}-\rho_{2}$, and $\rho_{2}^{\prime}-$ $\rho_{3}^{\prime}<\rho_{2}-\rho_{3}$. Therefore, the potential energy increases over the shelf and decreases in the Gulf Stream.

The winds, on the other hand, are more effective in changing the $K_{n}$, and this results in a $25 \%$ reduction of the $K_{m}$ in the mixed layer. The subsurface increase on the anticyclonic shear side of the stream is associated with the offshore displacement of the stream due to the southerly winds during the first half of the storm event (Xue et al. 1995). The input of kinetic energy by the winds stimulates vigorous mechanical mixing in the mixed layer, which results in lifting of the cold water and thereby increasing available potential energy in the mixed layer. Second, a seaward Ekman flow generated 
(a)
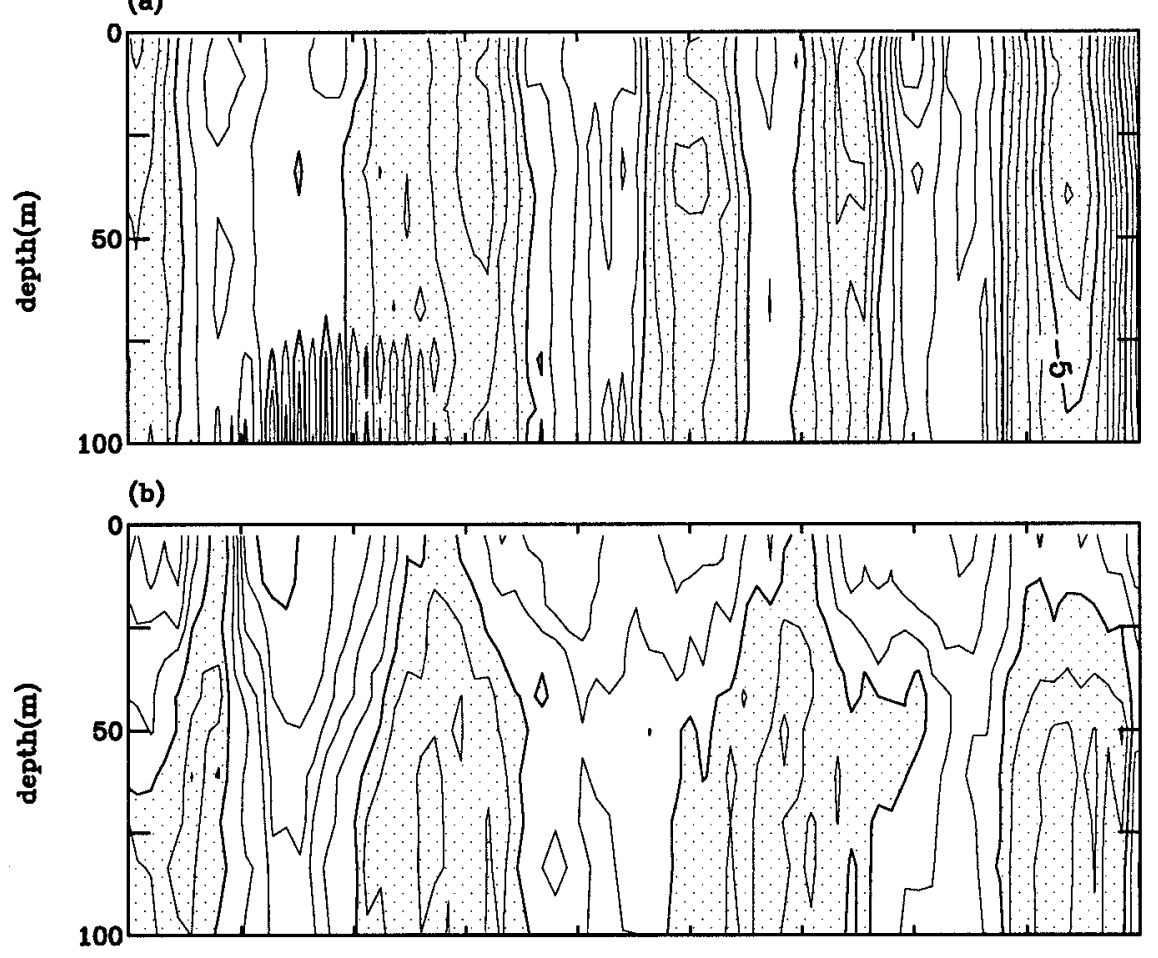

(c)

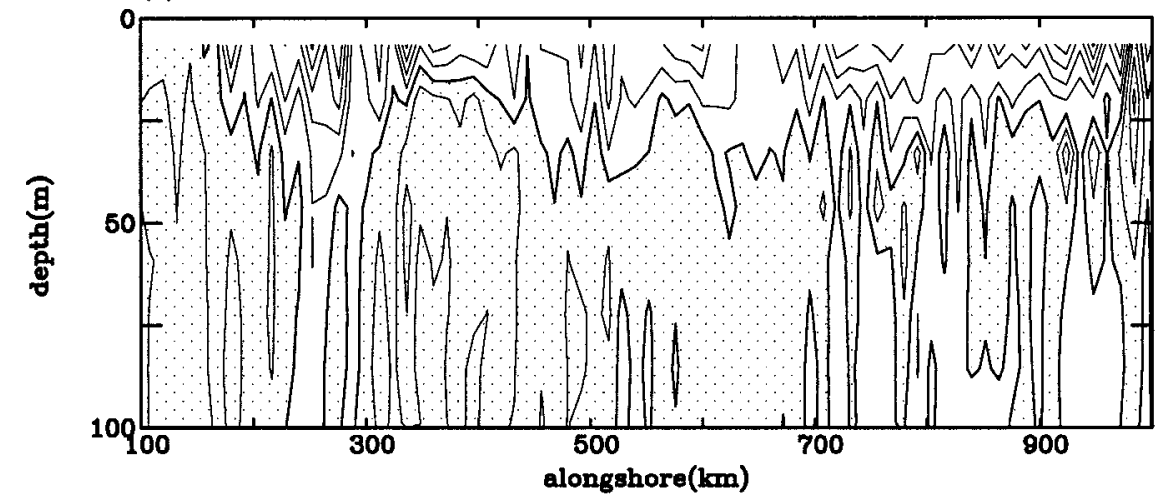

FIG. 18. Time-integrated (over the 5-day storm cycle) cross-shore heat flux, scaled by $10^{12} \mathrm{~J}$ $\mathrm{m}^{-2}$. Contour interval is 1 . (a) At $x=164 \mathrm{~km}$, the western boundary of the Gulf Stream, which is also the center location of the shoreward side meanders; (b) at $x=248 \mathrm{~km}$, the center location of the seaward side meanders; and (c) at $x=284 \mathrm{~km}$, roughly the eastern boundary of the stream.

by the southerly winds in the first half of the storm event advects the Gulf Stream offshore. From the schematic diagram in Fig. 16, as the lighter water $\left(\rho_{3}\right)$ is pushed offshore, the available potential energy increases on the right side, and decreases on the left side of the lighter water. The net effect of mixing and the displacement can be seen in the Fig. 15b. The $P_{m}$ (middle panel) increases in the shelf water, decreases on the shoreward side of the stream core (left of the solid triangle), and increases on the seaward side of the stream (right of the solid triangle). The $K_{m}$ and the $P_{m}$ in the combined experiment respond to both forcing, and the result is very much like a simple superposition.
Changes in $K_{e}$ and $P_{e}$ due to cooling and winds are shown in Figs. $15 \mathrm{c}$ and $15 \mathrm{~d}$. Although the largest $K_{m}$ decrease is on the shoreward side of the Gulf Stream, the decrease in $K_{e}$ there is relatively small. Therefore, the shoreward side meanders are not significantly affected. On the other hand, the decrease of the $K_{e}$ on the seaward side of the stream is rather significant, about half in the wind and the combined experiments when compared with the $K_{e}$ shown in the Fig. 14. The decrease in $K_{e}$ in the wind and the combined experiments corresponds to the clockwise circulation seen in Figs. 9b and $9 \mathrm{c}$, in a manner that weakens the seaward side meanders. From the point of view of energy conversion, 


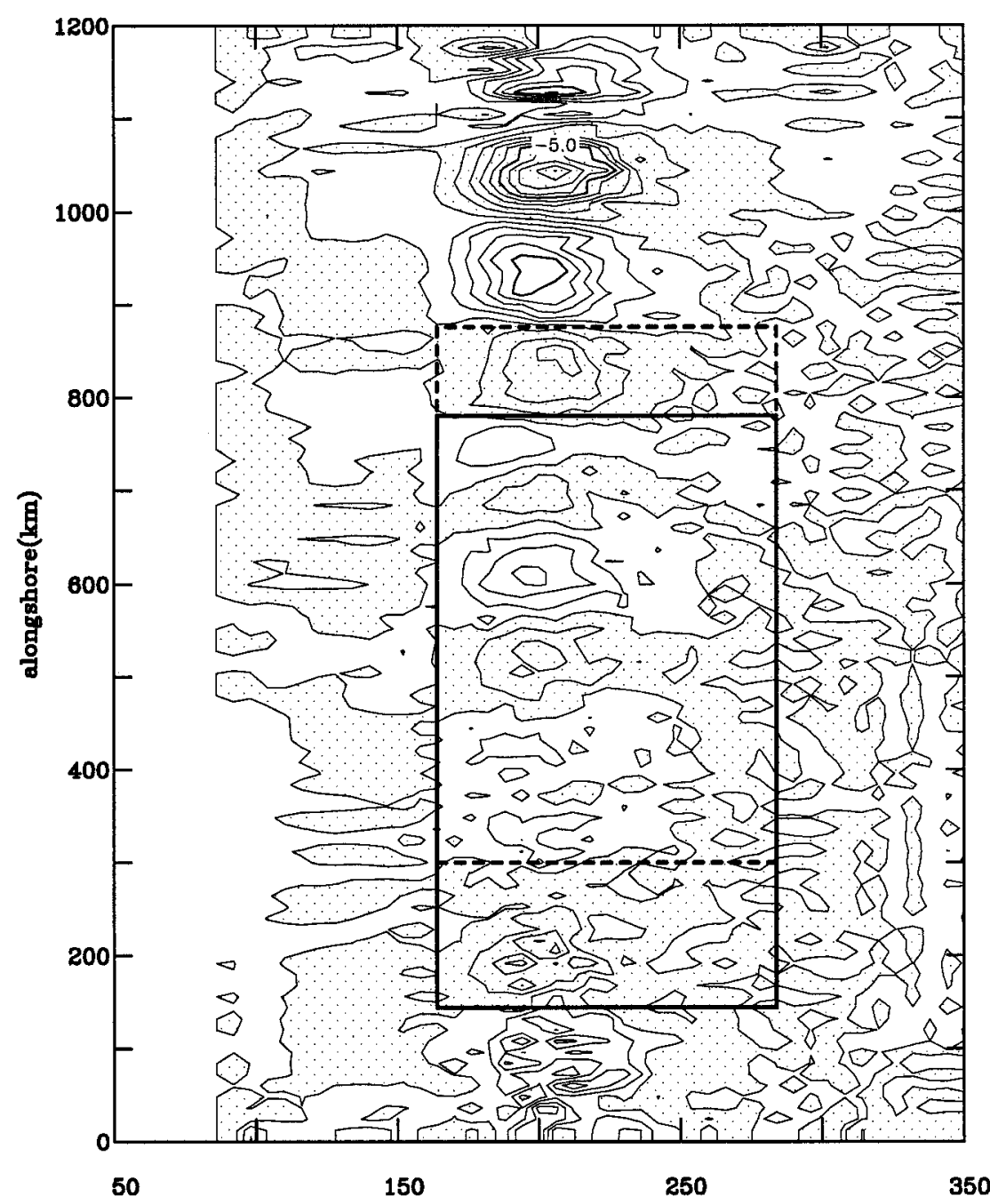

FIG. 19. Time-integrated (over the 5-day storm cycle) vertical heat flux at 100-m depth, scaled by $10^{10} \mathrm{~J} \mathrm{~m}^{-2}$. Contour interval is 1 . Two control volumes used for heat budget calculations are shown in a bold solid rectangle (from a crest to a trough) and a bold dashed rectangle (from a trough to a crest).

the decrease in $K_{e}$ results from the weakening of the baroclinic instability there. There is much less $K_{e}$ on the seaward side due to the decrease of the $P_{m}$ in the experiments forced by the cooling. Correspondingly, less $P_{e}$ is converted to $K_{e}$. The net change of $P_{e}$ in the wind experiment is probably small. Instead, the two regions of active eddies have been moved offshore, consistent with the offshore displacement of the Gulf Stream. In all three forced experiments, the decrease in $P_{e}$ left of the open triangle is consistent with the weakening of the warm filaments shown in Fig. 10. Additionally, the substantial decrease in $P_{e}$ to the right of the solid triangle in the combined experiment is consistent with the weakening of the seaward side meanders shown in Fig. 10. The $P_{e}$ increase at the core of the Gulf Stream in the cooling and the combined experiments in particular are associated with the north-south temperature gradient discussed earlier.

\section{c. Heat budget}

The ocean-to-atmosphere heat flux is the predominant forcing in both environments during cold air outbreaks. Understanding the oceanic source of this heat flux has been one of the primary goals of Goodman (1990), Xue et al. (1995), and Kelly and Qiu (1995). They suggested that in the region of the Gulf Stream the major balance of heat is established between the heat loss at the airsea interface and the reduction of heat content within the mixed layer. Following Xue et al. (1995), the heat budget is analyzed here using the balance equation obtained by integrating the heat conservation equation within a control volume over a 5-day storm cycle. This balance equation is

$$
\Delta H=H_{e}+H_{w}+H_{y}+H_{b}+H_{\mathrm{sen}+\mathrm{lat}}+H_{\mathrm{sw}}+H_{\mathrm{lw}},
$$


where $\Delta H$ is the heat content change within the control volume; $H_{e}$ and $H_{w}$ are the heat exchanges through the eastern and the western boundary of the volume, $H_{y}$ is the net change due to the downstream transport of heat, $H_{b}$ is the heat exchange through the bottom of the volume, and $H_{\text {sen+lat }}$ is the sum of the sensible and latent heat across the ocean-atmosphere interface; $H_{\mathrm{sw}}$ and $H_{\mathrm{lw}}$ are the net shortwave and longwave radiation, but both are excluded from the model calculations.

Changes in the water column heat content have been calculated for the present three-dimensional model study. The ratio between the decrease in heat content and the heat lost to the atmosphere is shown in Fig. 17. It is clear that the heat released from the ocean to the atmosphere comes mostly from the upper portion of the water column, with about $65 \%$ from the top $50 \mathrm{~m}, 87 \%$ from the top $100 \mathrm{~m}$, and $98 \%$ from the top $200 \mathrm{~m}$. Also shown in Fig. 17 is the ratio for the upper water column in the Gulf Stream. In the calculation, the western side of the stream boundary is the initial location of the surface temperature front (the open triangle). The eastern boundary of the stream is placed to give a stream width of $120 \mathrm{~km}$. The ratio is consistent with that of the whole domain.

One pertinent question: Are exchanges of heat between the Gulf Stream and the surrounding waters small? Heat budget computations using Eq. (6) reveal rather complex heat balances in the Gulf Stream because of downstream propagation and amplification of meanders. Any fixed control volume is inadequate to illustrate all of the processes. To demonstrate this, heat flow through various cross sections are shown in Figs. 18 and 19. Figure 18a shows the cross-stream heat flow at the onshore boundary of the stream, where the signatures of the onshore meanders are obvious. Since the shoreward flows carry warm Gulf Stream water and the seaward flows carry cold shelf water, negatives are stronger than positives. The stream is expected to lose heat to the shelf due to these meanders. Similarly, the stream also loses heat to the Sargasso Sea due to the offshore meanders as seen in Fig. 18b. Positives are dominant at this location also because of the offshore movement of the stream in response to the wind, which is clear in Fig. 18c where the effects of meanders are small and the heat flow comes mostly from the winddriven circulation (i.e., offshore at the surface and onshore below the mixed layer). Heat flows through a horizontal plane also show strong signatures of meanders (Fig. 19). In general, downward heat flows (negatives) are stronger than upward heat flows (positives) because upwelling carries cold water. However, the pattern is complicated by the downstream amplification of the meanders. A control volume beginning at a meander crest (the bold solid rectangle in Fig. 18) and a control volume beginning at a meander trough (the bold dashed rectangle in Fig. 18) result in rather different estimates of net upward heat flow. The downstream heat flow at any given $x-z$ plane (not shown) is by far the largest.
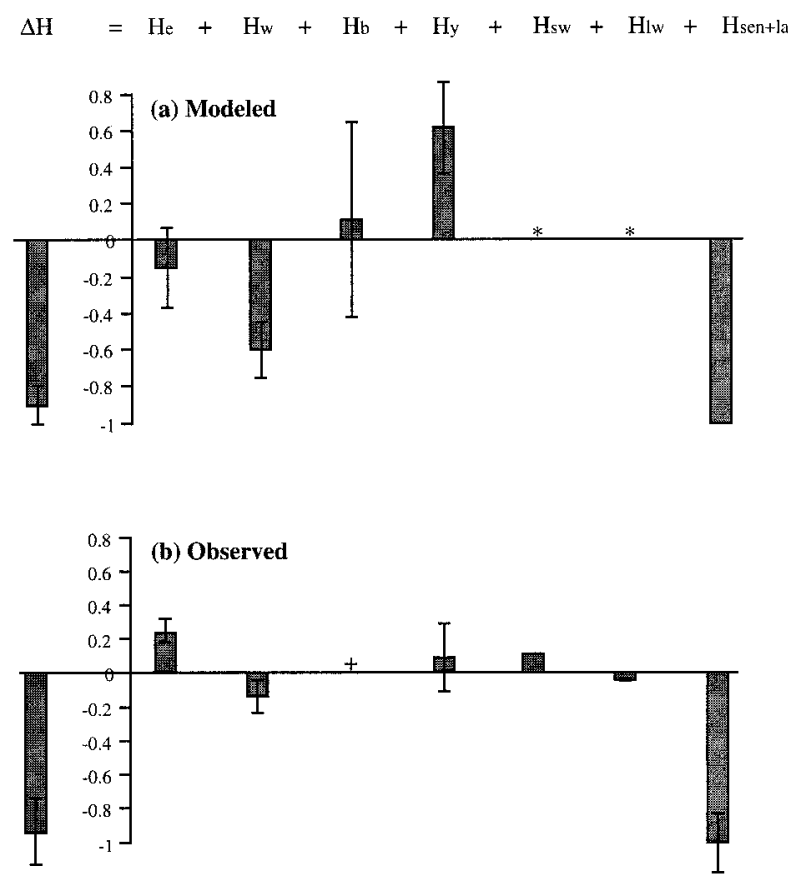

FIG. 20. Heat budget based on (a) the model results and (b) the observed data [adapted from Goodman (1990)]. The term denoted by a + is artificially set to zero in the observed heat budget; terms denoted by an * are not included in the model computations.

However, like $\Delta H$, only the net contribution from two subsequent $x-z$ planes (which form the southern and the northern end of the control volume) counts in the heat balance.

The presence of meanders affects the choice of control volume. To overcome this, two primary control volumes, a solid rectangle (from a crest to a trough) and a dashed rectangle (from a trough to a crest) in Fig. 19, are chosen. Each rectangle is about $600 \mathrm{~km}$ in the alongshore direction, which is about the length of the SAB. Regions close to the open boundaries are excluded in the heat budget calculations. The base of each control volume is set at 100-m depth, which is below the mixed layer at most places. The lateral boundary of each of these two primary control volumes moves in the crossshore direction with the shoreward side boundary of the control volume varying from $118 \mathrm{~km}$ to $164 \mathrm{~km}$ offshore. The above procedure results in a total of 14 control volumes that are used to estimate the mean and the standard deviation of each term in the heat balance equation. The result is shown in Fig. 20, in terms of ratios to the $H_{\text {sen+lat }}$.

In each case, the change of heat content and the heat loss from the ocean to the atmosphere are the two largest terms. The heat gain in the downstream direction and the heat loss from the Gulf Stream to the shelf water are each about $60 \%$ of either of the previous two terms, and almost balance each other. The other two terms, the heat exchange between the Gulf Stream and the Sargasso Sea and the heat exchange between the upper 
water column and the deeper jet, both have a small mean and a standard deviation much greater than the mean. The result is that the heat flow can go either direction. Figures 17 and 20 suggest that the effects of meanders in the heat budget seem to act separately from the severe cooling episodes during which the amount of oceanic heat release to the atmosphere is closely balanced by the heat decrease within the upper layer of the Gulf Stream, a result consistent with the two-dimensional study of the Xue et al. (1995) in which meanders were absent. Regardless of the severe cooling episodes, meanders transport heat from the Gulf Stream to the shelf water, and as a result the Gulf Stream exports less heat to the north than the input at the south (a net heat gain in the downstream direction). The second balance may be enhanced in the presence of a severe cooling episode. For comparison Fig. 20b, adopted from Goodman (1990), shows the estimates based on observed data. It must be pointed out that the estimates of $H_{y}$ and $H_{e}$ in Fig. 20b contain large uncertainties due to the lack of direct velocity measurements during GALE. Here $H_{w}$ was obtained using data from a single current mooring, which may not represent all the eddy transport as it varies greatly in the downstream direction (see Fig. 18a). Nevertheless, the close balance between the heat decrease in the upper layer of the Gulf Stream and the heat release to the atmosphere is the same in the observed data and the model.

\section{Summary}

The three-dimensional, primitive equation, Princeton Ocean Model is used to examine the modifications of the Gulf Stream and its meanders by intense, wintertime, atmospheric cooling episodes. As expected and in agreement with our previous two-dimensional study, the mixed layer deepens and the mixed layer temperature decreases. SST generally decreases by about $2^{\circ} \mathrm{C}$, although more on the shoreward side of the stream where the cooling is strongest. SST increases slightly near the seaward side front of the Gulf Stream due to the offshore wind-driven displacement of the stream. The modifications of the Gulf Stream are not uniform in the downstream direction, although the forcings are in the model cases. Warm filaments are cooled more with SST decreases by about $3^{\circ} \mathrm{C}$.

Two types of meanders are found in the model. Meanders on the shoreward side of the Gulf Stream are unstable baroclinic waves. They are affected little by the imposed atmospheric forcing because their energy source is the $P_{m}$ stored at the permanent thermocline, which extends to hundreds of meters depth, well below the mixed layer. Meanders on the seaward side of the Gulf Stream are both barotropically and baroclinically unstable. Here $P_{m}$ stored at the surface front separating the Gulf Stream and the Sargasso Sea feeds these meanders. This $P_{m}$ can be reduced by the effect of a cold air outbreak. Thus, these meanders lose strength and also seem to slow in their downstream propagation due to the southward Ekman flow generated by the strong westerly wind during an outbreak.

The input of momentum by the wind forms an Ekman balance. Below the mixed layer, the geostrophic balance dominates in the cross-stream direction. Nonlinear advection of momentum, at its greatest at locations of "backward breaking," is about $20 \%$ of the Coriolis term in the cross-stream direction and about half of the Coriolis term in the downstream direction.

Heat budget calculations seem to suggest two almost separable processes. The oceanic heat release to the atmosphere during these severe cooling episodes comes almost exclusively from the upper water column. Transport of heat by meanders is large, especially from the Gulf Stream to the shelf; however, it does not disrupt the principal balance. It is balanced nicely by the net heat transport in the downstream direction. We suggest that in the absence of severe cooling, eddy transport of heat from the Gulf Stream to the shelf and the moderate ocean-to-atmosphere latent and sensible heat flux are balanced with the net heat transport by the stream in the downstream direction, whereas in the presence of severe cooling, the former balance remains, and the extra ocean-to-atmosphere latent plus sensible heat flux is compensated by the loss of heat from the upper water column.

Acknowledgments. We are very pleased to acknowledge the supercomputer time that was provided by the North Carolina Supercomputing Center. This work was supported by National Science Foundation Grants OCE9314198 to the University of North Carolina and OCE9508165 to University of Maine.

\section{APPENDIX}

\section{Open Boundary Conditions}

\section{a. External mode}

Transport is specified at the inflow southern boundary such that $D \bar{v}$ is fixed at its initial value, where $D$ is the depth of the water column and $\bar{v}$ is the vertically averaged downstream velocity. At the eastern and northern boundary, velocity normal to the open boundary, $\bar{u}_{n}$, is calculated using the following:

$$
H \bar{u}_{n}-\sqrt{g H \eta}=\mathrm{BC},
$$

where $\eta$ is the surface elevation, $H$ is the depth, and $\mathrm{BC}$ takes the initial value of the left-hand side of Eq. (A1). An upwind advective scheme is applied to the velocity component tangential to the boundary:

$$
\frac{\partial \bar{u}_{t}}{\partial t}+\bar{u}_{n} \frac{\partial \bar{u}_{t}}{\partial n}=0 .
$$

In case of inflow, the value of $\bar{u}_{t}$ being advected to the domain is set to zero. 


\section{b. Internal mode}

Internal velocities normal to the open boundaries are calculated using the following radiation condition:

$$
\frac{\partial u_{n}}{\partial t}+c_{i} \frac{\partial u_{n}}{\partial n}=0
$$

where $c_{i}=\left(\Delta n / \Delta t_{i}\right) \sqrt{H / H_{\max }}, \Delta t_{i}$ is the internal time step, and $H_{\max }$ is the maximum depth. Mellor (1996) justifies this seemingly crude approximation assuming that the $\Delta t_{i}$ used in the model maximizes $c_{i} \Delta t_{i} / \Delta n$ (near unity) when approaching maximum depth. An upwind advective scheme similar to (A2) is used for the velocity component tangential to the open boundary and temperature. In case of inflow, the values being advected into the domain are set to zero and the initial temperature, respectively.

\section{REFERENCES}

Adamec, D., and R. L. Elsberry, 1985: Numerical simulations of the response of intense ocean currents to atmospheric forcing. $J$. Phys. Oceanogr., 15, 273-287.

Atkinson, L. P., E. Oka, S. Y. Wu, T. J. Berger, J. O. Blanton, and T. N. Lee, 1989: Hydrographic variability of southeastern United States shelf and slope waters during the Genesis of Atlantic Lows Experiment: Winter 1986. J. Geophys. Res., 94, 10 699-10 713.

Bane, J. M., Jr., and K. E. Osgood, 1989: Wintertime air-sea interaction processes across the Gulf Stream. J. Geophys. Res., 94, $10755-10772$.

- D. A. Brooks, and K. R. Lorenson, 1981: Synoptic observations of the three-dimensional structure and propagation of the Gulf Stream meanders along the Carolina continental margin. J. Geophys. Res., 86, 6411-6425.

Blanton, J. O., J. A. Amft, D. K. Lee, and A. Riordan, 1989: Wind stress and heat fluxes observed during winter and spring 1986 J. Geophys. Res., 94, 10 686-10 698.

Blumberg, A. F., and G. L. Mellor, 1987: A description of a threedimensional coastal ocean circulation model. Three-Dimensional Coastal Ocean Models, Vol. 4, N. Heaps, Ed., Amer. Geophys. Union, $208 \mathrm{pp}$

Budyko, M. I., 1974: Climate and Life. Academic Press, 508 pp.

Dewar, W. K., and J. M. Bane Jr., 1985: Subsurface energetics of the Gulf Stream near the Charleston Bump. J. Phys. Oceanogr., 15, 1771-1789.

Doyle, J. D., and T. T. Warner, 1990: Mesoscale coastal processes during GALE IOP2. Mon. Wea. Rev., 118, 283-308.

— , and _ 1993: A three-dimensional numerical investigation of a Carolina coastal low-level jet during GALE IOP2. Mon. Wea. Rev., 121, 1030-1047.

Goodman, L. M., 1990: The heat budget of the Gulf Stream during strong atmospheric forcing. M.S. thesis, The University of North Carolina at Chapel Hill, $56 \mathrm{pp}$.

Grossman, R. L., and A. K. Betts, 1990: Air-sea interaction during an extreme cold air outbreak from the eastern coast of the United States. Mon. Wea. Rev., 118, 324-342.

Hobbs, P. V., 1987: The Gulf Stream rainband. Geophys. Res. Lett., 14, 1142-1145.

Holt, T., and S. Raman, 1990: Marine boundary-layer structure and circulation in the region of offshore redevelopment of a cyclone during GALE. Mon. Wea. Rev., 118, 392-410.
Huang, C. Y., and S. Raman, 1992: A three dimensional numerical investigation of a Carolina coastal front and the Gulf Stream rainband. J. Atmos. Sci., 49, 560-584.

Huang, R. X., 1990: Does atmospheric cooling drive the Gulf Stream recirculation? J. Phys. Oceanogr., 20, 751-757.

Isemer, H.-J., and L. Hasse, 1987: The Bunker Climate Atlas of the North Atlantic Ocean. Vol. 2: Air-Sea Interactions, SpringerVerlag, $252 \mathrm{pp}$

Kelly, K. A., and B. Qiu, 1995: Heat flux estimates for the western North Atlantic. Part II: The upper-ocean heat balance. J. Phys. Oceanogr., 25, 2361-2373.

Large, W. G., and G. B. Crawford, 1995: Observations and simulations of upper-ocean response to wind events during the Ocean Storms experiment. J. Phys. Oceanogr., 25, 2831-2852.

Lee, T. N., L. P. Atkinson, and R. Legeckis, 1981: Observations of a Gulf Stream frontal eddy on the Georgia continental shelf, April 1977. Deep-Sea Res., 28A, 347-378.

— E. Williams, J. Wang, and R. Evans, 1989: Response of South Carolina continental shelf waters to wind and Gulf Stream forcing during winter of 1986. J. Geophys. Res., 94, 10 715-10 754.

_ fluence on productivity of the southeast U.S. continental shelf. J. Geophys. Res., 96, 22 191-22 206.

Martin, P. J., 1985: Simulation of the mixed layer at OWS November and Papa with several models. J. Geophys. Res., 90, 903-916.

Mellor, G. L., 1991: An equation of state for numerical models of oceans and estuaries. J. Atmos. Oceanic Technol., 8, 609-611.

—_, 1996: Users guide for a three-dimensional, primitive equation, numerical ocean model. Princeton University, $39 \mathrm{pp}$.

— model for geophysical fluid problems. Rev. Geophys. Space Phys., 20, 851-875.

Nakamura, N., 1988: Scale selection of baroclinic instability-Effects of stratification and nongeostrophy. J. Atmos. Sci., 45, 32533267.

Newton, C., and E. Holopainen, Eds., 1990: Extratropical Cyclones: The Erik Palmen Memorial Volume. Amer. Meteor. Soc., 262 pp.

Nof, D., 1983: On the response of ocean currents to atmospheric cooling. Tellus, 35A, 60-72.

Schmitt, R. W., P. S. Bogden, and C. E. Dorman, 1989: Evaporation minus precipitation and density fluxes for the North Atlantic. $J$. Phys. Oceanogr., 19, 1208-1221.

Smagorinsky, J., 1963: General circulation experiments with the primitive equations. Part I: The basic experiment. Mon. Wea. Rev., 91, 99-164.

Wash, C. H., S. M. Heikkinen, C.-S. Liou, and W. A. Nuss, 1990: A rapid cyclogenesis event during GALE IOP9. Mon. Wea. Rev., 118, 375-391.

Webster, F., 1961: A description of Gulf Stream meanders off Onslow Bay. Deep-Sea Res., 8, 130-143.

Worthington, L. V., 1976: On the North Atlantic Circulation. The Johns Hopkins University Press, 110 pp.

_ 1977: Intensification of the Gulf Stream after the winter of 1976-1977. Nature, 270, 415-417.

Xue, H., 1991: Numerical studies of Gulf Stream meanders in the South Atlantic Bight. Ph.D. dissertation, Princeton University, 188 pp. [UMI No. 91-35862.]

, and G. L. Mellor, 1993: Instability of the Gulf Stream front in the South Atlantic Bight. J. Phys. Oceanogr., 23, 2326-2350.

- J. M. Bane, and L. M. Goodman, 1995: Modification of the Gulf Stream through strong air-sea interactions in winter: Observations and numerical simulations. J. Phys. Oceanogr., 25, 533-557. 